REVIEW ARTICLE

\title{
Voyage inside the cell: Microsystems and nanoengineering for intracellular measurement and manipulation
}

\author{
Jun Liu, Jun Wen, Zhuoran Zhang, Haijiao Liu and Yu Sun
}

Properties of organelles and intracellular structures play important roles in regulating cellular functions, such as gene expression, cell motility and metabolism. The ability to directly interrogate intracellular structures inside a single cell for measurement and manipulation has significant implications in the understanding of subcellular and suborganelle activities, diagnosing diseases, and potentially developing new therapeutic approaches. In the past few decades, a number of technologies have been developed to study single-cell properties. However, methods of measuring intracellular properties and manipulating subcellular structures have been largely underexplored. Due to the even smaller size of intracellular targets and lower signal-to-noise ratio than that in wholecell studies, the development of tools for intracellular measurement and manipulation is challenging. This paper reviews emerging microsystems and nanoengineered technologies for sensing and quantitative measurement of intracellular properties and for manipulating structures inside a single cell. Recent progress and limitations of these new technologies as well as new discoveries and prospects are discussed.

Keywords: atomic force microscopy (AFM); fluorescent proteins and molecules; intracellular manipulation; intracellular measurement; MEMS; nanoparticle; nanotube; nanowire

Microsystems \& Nanoengineering (2015) 1, 15020; doi:10.1038/micronano.2015.20; Published online: 14 September 2015

\section{INTRODUCTION}

Inside a living cell, numerous biological processes and biochemical reactions occur in the subcellular organelles, which are often compartmentalized and dynamically change intracellular physical and chemical properties, for instance, temperature ${ }^{1,2}$, pressure ${ }^{3}$, mechanical ${ }^{4,5}$ and electrical characteristics ${ }^{6}, \mathrm{pH}^{7}$, and concentrations of ions and other molecules ${ }^{8,9}$. These processes, such as the production of ATP by mitochondria or protein synthesis by ribosomes, require intracellular homeostasis to maintain normal cellular functions. Therefore, it is not surprising that each property is strictly regulated and varies among different intracellular structures and organelles. Tracking the regulation of these quantities could reveal largely underexplored subcellular functions and mechanisms. Moreover, an increasing body of evidence has indicated close correlations between intracellular disorders and diseases. For example, abrupt changes in intracellular electrical current propagation across cells are closely related to cardiac arrhythmia ${ }^{10,11}$, which is the leading cause of death worldwide ${ }^{12}$. Abnormalities in cell apoptosis, which can result from $\mathrm{pH}$ regulation disorders ${ }^{13}$, can lead to cancers $^{14}$. Thus, monitoring intracellular environments and quantitatively measuring intracellular properties would enable us to better understand subcellular activities and disease mechanisms and potentially develop new therapies via rescuing/altering subcellular functions.

Directly measuring the properties of organelles and intracellular structures in a living cell is difficult. Early research attempted to use glass micropipettes and microelectrodes to measure cytoplasmic $\mathrm{pH}^{15}$, pressure ${ }^{16}$ and electrical properties ${ }^{17}$. However, these direct measurements were mostly made on an entire cell due to spatial limitations of these technologies. Compared to the measurement of whole cells (typically tens of micrometers in size), the characterization of organelles and intracellular structures requires finer spatial positioning accuracy and much more miniaturized sensing tips. In addition, signals measured from intracellular structures are often weak and differ minutely inside a cell. For instance, subcellular temperature variations in different locations in a cell are only within a tenth of one degree $^{18}$. To measure intracellular properties, microsystems and nanoengineered tools developed for this purpose must have high measurement sensitivities and resolutions.

The past few years have witnessed exploratory efforts in the development of new tools and techniques for direct intracellular measurement and manipulation. Recent studies have shown direct measurement of the mechanical properties of the nuclear membrane ${ }^{19}$, and intracellular potentials and intracellular $\mathrm{pH}$ of cardiomyocytes or neuronal cells have been characterized ${ }^{20}$. In this paper, we review the emerging tools and technologies for intracellular measurement and manipulation. The reviewed intracellular sensing techniques are classified into two categories: tethered measurement methods (nanowires, nanotubes and modified atomic force microscopy (AFM) probes) and untethered sensing approaches (nanoparticles, fluorescent proteins (FPs) and molecules, and untethered microelectromechanical system (MEMS) devices). The tethered sensing technologies are often invasive to the cell membrane or inner structures due to the connected peripheral measuring structures, whereas the untethered sensors, after being delivered into a cell or produced by inherent cellular machinery, induce minimal or no damage to the cell. The intracellular properties reviewed here are mechanical properties (e.g., stiffness and viscosity), electrical properties (e.g., transmembrane potentials), other physical properties (e.g., temperature and pressure), and biochemical properties (e.g., $\mathrm{pH}$ value and ion concentration). Figure 1 graphically depicts representative intracellular properties and measurement techniques. 


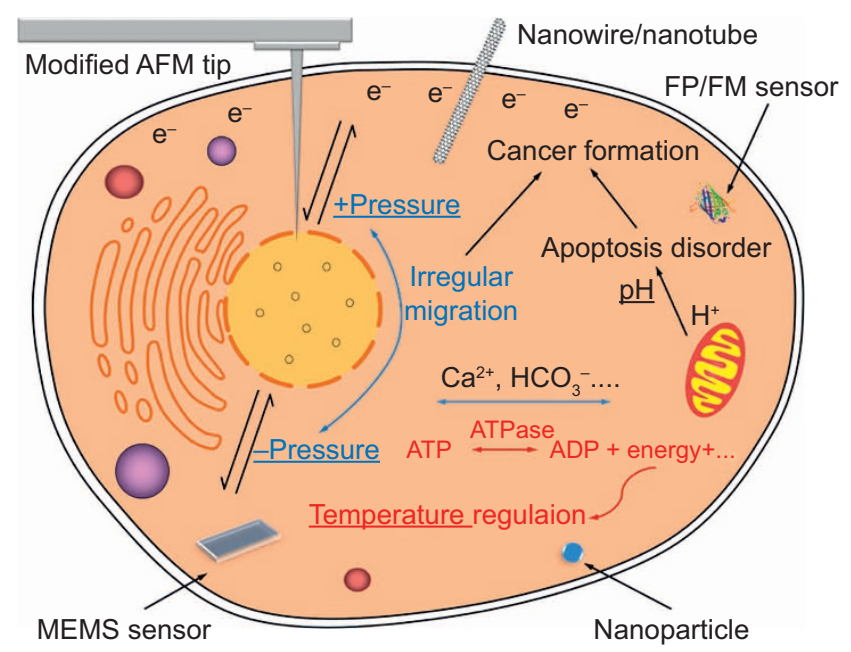

Figure 1 Schematic showing representative intracellular properties and their measurement techniques. For instance, the temperature distribution inside a cell has been measured by nanoparticles because abnormal temperature changes can significantly influence cell activities, such as gene expression and protein synthesis; and electrical quantities have been measured by tethered nanowire/ nanotube devices because intracellular electrical properties play essential roles in maintaining normal functions in the heart and central nervous system.

Additionally, we discuss intracellular manipulation techniques that are often needed for direct measurements inside living cells.

\section{TETHERED INTRACELLULAR SENSING}

In tethered sensing, an intracellular probe transforms detected intracellular quantities into electrical or photonic signals and transmits the signals to external instruments via tethering connections. The glass micropipette is the oldest tethered probe that is still widely used today. As early as in 1970s, the patch clamp technique with micropipettes was used to record the intracellular potential and single ion channel current ${ }^{21,22}$. Glass micropipettes are simple to use and are inexpensive to fabricate. However, for subcellular studies, making ultrafine glass micropipette tips consistently to achieve minimal damage to cells can be challenging. Due to the fragility of glass tips at the nanoscale, glass micropipettes are easily broken. To overcome these limitations, other probes have been developed using nanowires, carbon nanotubes (CNTs), and modified AFM tips. These probes are small (e.g., $100 \mathrm{~nm}$ ) to minimize cell damage and avoid significant perturbations to normal cellular activities. They are fabricated with small apex angles to enable deep insertion into cells or organelles and to have minimal influence on neighboring intracellular structures. When scaled up, arrays of vertical sensing probes (e.g., multielectrode arrays (MEAs)) are able to provide high-throughput, parallel intracellular measurement.

\section{Nanowires and nanotubes}

\section{Intracellular electrical measurement}

Normal intracellular electrical activities (e.g., ion flows and translocation of charged molecules) are of great importance for the maintenance of regular cell functions, such as those in cardiomyocytes and neuronal cells. Disorders in ion flows through gap junction channels are one of the major causes of cardiac arrhythmia ${ }^{10,23}$. Irregular intracellular $\mathrm{pH}$ levels, due to imbalanced proton concentrations caused by dysfunction of mitochondria, can result in severe central nervous system disorders, such as
Parkinson's disease ${ }^{24,25}$. To measure intracellular electrical properties, such as transmembrane potential and the concentration of charged molecules, nanowires, and CNTs have been used as measurement tools.

A nanowire has a diameter on the nanometer scale and a high aspect ratio. Electrons transported in nanowires are quantum confined laterally, in contrast to electron transport in three-dimensional bulk materials, and thus, the conductivity is much less than that of corresponding bulk materials ${ }^{26}$. Moreover, edge effects (i.e., atoms on the surface not fully bonded to neighboring atoms) exist in nanowires, making them suitable for building semiconductor devices, such as field effect transistors $(\mathrm{FETs})^{27}$. In traditional cell electrophysiology, the intracellular electrical signal is detected by electrodes inserted into a glass micropipette, which is then amplified by an FET-based amplifier. Using a nanowire, the detection electrode and FET amplifier can be built together to form a small sensing probe. The small size of a nanowire probe enables higher spatial resolution and minimizes the damage to the cell membrane and intracellular structures. When directly inserted into a single cell, nanowires operate as tunable conducting channels with a short response time. Furthermore, the sensitivity of nanowire devices is significantly increased due to the high surface-to-volume ratios of nanowires.

For direct intracellular electrical recordings, 3D FET devices based on kinked silicon nanowires (Figure 2a) have been developed $20,28,29$. Because of the sub-10 nm size and minimal interfacial impedance, the 3D nanoFET does not cause noticeable damage to the cell membrane. The nanowire-based devices have been shown to be capable of measuring both intracellular potential and $\mathrm{pH}$ in embryonic chicken cardiomyocytes. The 3D nanoFET modified with phospholipid bilayers can enter single cells with minimal or no invasiveness and thus allow robust recording of electrical signals. The measured full amplitude of intracellular potentials $(\sim 75-100 \mathrm{mV})$ has confirmed that a tight seal can be formed between the nanowire surface and the cell membrane, resulting in no putative probe/ membrane electrical leakage. Analyses of recorded voltage signals have revealed five characteristic phases of a cardiac intracellular potential: resting state, rapid depolarization, plateau, rapid repolarization and hyperpolarization. Additionally, a sharp transient peak and a notch possibly associated with the inward sodium and outward potassium currents $^{30}$ have also been observed. Due to the intrinsic advantage in electrical properties of silicon nanowires, the FET device can achieve a high sensitivity for conductance measurement $\left(4-8 \mu \mathrm{S} \mathrm{V}^{-1}\right)$ and for $\mathrm{pH}$ measurement $\left(58 \mathrm{mV} \mathrm{pH}^{-1}\right)$.

One advantage of the nanowire-based FET device over traditional glass micropipettes is that there is no need for resistance or capacitance compensation. Additionally, when directly inserted into single cells, nanoFETs are able to detect intracellular electrical signals without exchanging with cellular ions; hence, the interfacial impedance and biochemical disturbances to the cells are minimized. To further decrease the intracellular probe size, the same group has developed a branched nanoFET to bridge the intracellular environment and FET detector elements ${ }^{31,32}$. The branched nanoFET was formed by fabricating a hollow $\mathrm{SiO}_{2}$ structure on the silicon nanowire FET. During the etching step to remove the upper portion of $\mathrm{SiO}_{2}$, a controlled taper was achieved at the tip due to isotropic etching, which significantly reduces the probe size to $5 \mathrm{~nm}^{32}$. This small size enables direct measurements in the smallest intracellular structures, such as neuron dendrites and dendritic spines, which is difficult to achieve using conventional techniques. 

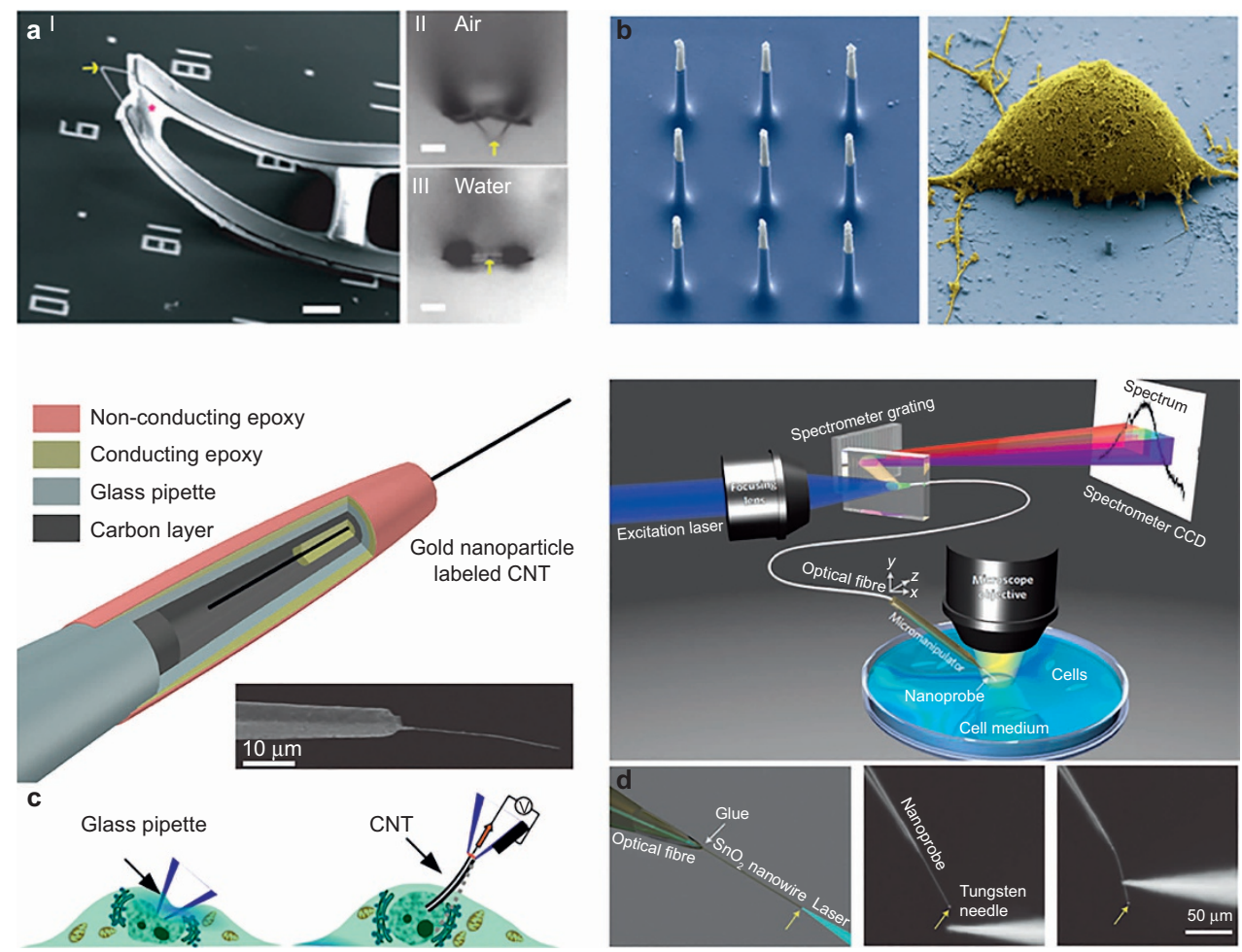

Figure 2 Nanowires and nanotubes for intracellular measurement. (a) A kinked silicon nanowire was used to form a 3D FET device for direct measurement of intracellular potentials. Reproduced with permission from Ref. 20. (b) Vertical electrode arrays based on silicon nanowires. Left: SEM image of nine vertical nanowire electrodes. Right: SEM image of a rat cortical cell on top of a vertical nanowire electrode array pad. Reproduced with permission from Ref. 33. (c) Multifunctional carbon nanotube endoscope in which the carbon nanotubes cause less damage to the cell structure than glass micropipettes with conical tips. Reproduced with permission from Ref. 34 . (d) $\mathrm{A} \mathrm{SnO}_{2}$ nanowire was fabricated on an optical fiber for intracellular optical measurement. Reproduced with permission from Ref. 35.

Arrays of vertical nanowire electrodes have also been developed to form MEAs for parallel intracellular electrical recordings (Figure $2 b)^{33,36-38}$. Although higher throughput is an advantage, concerns about using nanowire-based MEAs have also been raised because long-term culturing of cells with MEAs inside may perturb cell gene expression, proteomics, and other cell activities $^{39}$. Nanowire MEAs are not able to target specific cells, and accurately positioning the sensing tip inside a cell can also be difficult. In comparison, a free-standing nanoFET provides higher flexibility for probing intracellular structures three dimensionally.

In addition to nanowires, CNTs are also used for intracellular electrical recording ${ }^{40}$. A CNT is a tube-shaped nanostructure made of carbon atoms, with a diameter on the scale of nanometers and a high aspect ratio ${ }^{41}$. Because CNTs are one of the strongest and stiffest materials in terms of tensile strength and elastic modulus ${ }^{42}$, CNT-based sensing devices, unlike glass micropipettes, are much more difficult to break. Moreover, with their exceptional carrier mobility and electric current density that are three orders of magnitude higher than typical metals, such as copper and aluminium ${ }^{43}$, CNTs are suitable for detecting the weak signals within single cells. In 2009, Bau et al. have demonstrated the use of a carbon nanopipette to perform intracellular electrical measurements ${ }^{44,45}$. A conductive carbon layer was formed via chemical vapor deposition of carbon on the inside wall of a glass pipette. The pipette tip was then etched away, exposing a carbon tip with a tip diameter of 100 200 nm. The carbon nanopipettes were able to record intracellular electrical signals in mouse hippocampal cells (HT-22) with minimal membrane damage. Direct electrical measurement with the carbon nanopipette showed that an increase in the extracellular $\mathrm{K}^{+}$concentration produces a significant increase in the membrane potential (i.e., a higher depolarization). One limitation of the carbon nanopipette is that it has the inherited conical tip from the glass mold, which may cause damage to cell membranes when the tip is inserted deeper into a cell.

Another representative CNT device, reported by Singhal et al., has a CNT assembled at the tip of a glass pipette using

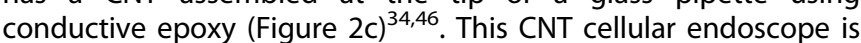
fabricated using a flow-through technique, which is more versatile than the magnetic assembly method ${ }^{47}$. The CNT endoscope is less invasive than traditional glass pipettes, as indicated by the statistical analysis of actin network stability and cytosolic calcium ion release. In addition to the small size, another reason for the minimal damage to the cell membrane is that CNTs with minimal surface defects exhibit nonpolar properties. Furthermore, this nonpolarity feature would enable the coupling between membrane-constituent lipids and the CNT surface, resulting in tight seals of cell membrane around the CNT probe ${ }^{48}$. The CNT device with a diameter of $\sim 100-200 \mathrm{~nm}$ requires a membrane penetration force ranging from a few hundreds of piconewtons to tens of nanonewtons ${ }^{49}$. During intracellular measurement, by confining the interaction between CNT and the first few layers of surrounding ions or molecules, the interference from the rest of the cell volume can be avoided, leading to an increase in sensitivity and selectivity. In addition to intracellular measurement of small amplitude of electrical signals, the CNT nanopipette can also probe single organelles and monitor the changes in mitochondrial membrane potential in response to nanopipette insertion. Mitochondria are important for maintaining intracellular $\mathrm{Ca}^{2+}$ homeostasis because of their ability to buffer $\mathrm{Ca}^{2+}$, especially 
in the case of calcium elevation ${ }^{50}$. In the experiment by Singhal et al., slight membrane hyperpolarization was observed in the mitochondria located near the CNT nanopipette tip, suggesting that the mitochondria sequestered $\mathrm{Ca}^{2+}$ from their surroundings and forced the generation of additional energy.

To decrease the fabrication difficulties encountered in the construction of CNT nanopipettes, Yoon et al. have developed a new self-entanglement method ${ }^{51}$. The self-entangled CNT tip is assembled through dielectrophoresis with an electrochemically sharpened tungsten probe and multi-walled CNTs dispersed in solution. The probe has been used for intracellular recordings from vertebrate neurons in vitro and in vivo. In electrical measurement, impedance is also an important property for studying cellular functions and activities. Yun et al. have synthesized CNTs into the shape of towers and have embedded them into microfluidic channels as electrodes ${ }^{52}$ for impedance measurement of LNCaP human prostate cancer cells. To achieve parallel measurement, CNTs or carbon nanofibers (bundles of CNTs) have been built into vertically aligned sensing arrays for monitoring cell electrical activities or delivering materials (e.g., plasmid DNA molecules) into cells ${ }^{53,54}$.

\section{Intracellular optical measurement}

For intracellular sensing using optical means, high-resolution optical detection is required and noise from neighboring sites must be minimized. Hence, researchers have developed near-field fluorescence imaging techniques to distinguish target signals from neighboring noise ${ }^{55,56}$. In near-field imaging, optical probes are directly inserted into single cells, and optical waves are transmitted to an external measurement instrument. Due to the small size and high efficiency in transmitting light, nanowires are excellent structures for building optical probes ${ }^{57,58}$. Using nanowires, Yan et al. have developed an optical intracellular endoscope that is able to accurately detect and record fluorescent signals (Figure $2 \mathrm{~d}$ ) ${ }^{35}$. The nanowire endoscope has a $\mathrm{SiO}_{2}$ nanowire waveguide fixed on the tapered tip of an optical fiber and is inserted into a cell by using a micromanipulator. The endoscope can be optically coupled to either an excitation laser to work as a local light source for subcellular imaging or a spectrometer to collect local optical signals. It is capable of sensing $\mathrm{pH}$ changes by coating the nanowire tip with a polymer embedded with $\mathrm{pH}$-sensitive dyes. Additionally, the endoscope is also able to collect fluorescence signals from a single quantum dot cluster in subcellular regions. Signal collection is highly sensitive to the distance between the quantum dot cluster and the nanowire tip, which enables high-resolution fluorescence mapping and probing of the interior of non-transparent living biological objects.

To detect the optical signal inside a cell, another device has been developed using GaAs nanowires. The device consists of photonic crystal cavities and functions as an intracellular nanoprobe for both sensing and photonic control ${ }^{59}$. The semiconductor nanocavity probe emits photoluminescence from embedded quantum dots and sustains high-quality resonant photonic modes inside a cell. The probes are minimally invasive to cells. They have been inserted into cells for days without interfering with regular cell division. After surface modification with biotin, the nanophotonic probes are able to perform in vitro label-free protein sensing to detect streptavidin.

\section{Modified AFM probes}

Standard AFM cantilevers have a conical or a pyramidal tip. There are a number of techniques for modifying the standard AFM tip. As shown in Figure 3a, a standard AFM tip has been modified, via focused ion beam (FIB), into a straight, long nanoneedle with a

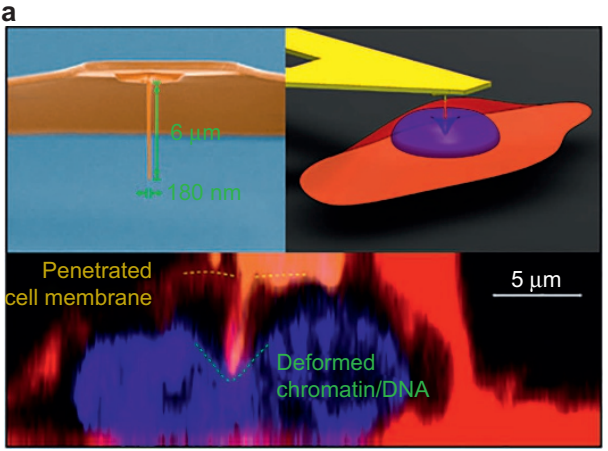

C

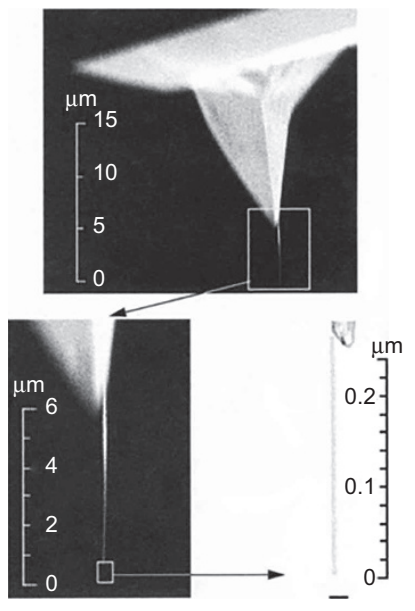

b
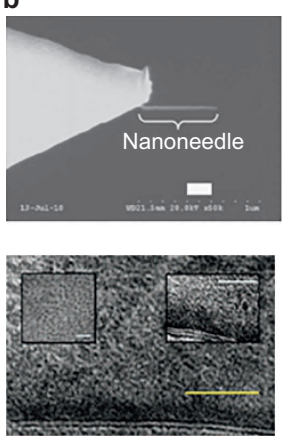

d

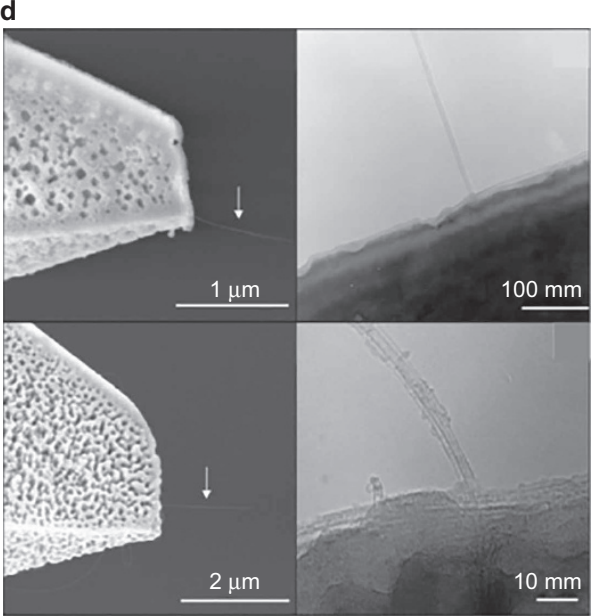

Figure 3 (a) Modified atomic force microscopy (AFM) tip for penetration into a single cell to measure the mechanical properties of a cell nucleus (adapted with permission from Ref. 19; Copyright (2014) American Chemical Society). (b) The electron beam-induced growth of AFM nanoneedles was used to penetrate into corneocytes. Reproduced with permission from Ref. 60. (c) A single multi-walled carbon nanotube (MWCNT) attached to a pyramidal tip. Reproduced with permission from Ref. 61. (d) SEM and TEM images of MWCNT and single-walled carbon nanotubes (SWCNT) fabricated by chemical vapor deposition and assembled onto a silicon cantilever/tip. Reproduced with permission from Ref. 62. 
a high aspect ratio structure of $100-300 \mathrm{~nm}$ in diameter and $2-20 \mu \mathrm{m}$ in length depending on the original height of the AFM tip ${ }^{63-65}$. Other techniques for modifying standard AFM tips involve the growth or assembly of nanowires or nanotubes on AFM tips (Figure $3 b-d)^{62,66-68}$. These modified tips are still an integral part of a standard AFM cantilever and thus are capable of performing high-resolution measurements or manipulation. These AFM nanoneedles are minimally invasive to cells, and their surfaces can be readily functionalized for specific applications.

Modified AFM tips for intracellular characterization need to be micrometers long and mechanically robust to penetrate cell membranes and probe intracellular structures or organelles ${ }^{19,60,64}$. Beard et al. have used an AFM nanoneedle to measure the elastic moduli of the internal keratin structures of corneocytes (Figure $3 b)^{60}$. A tomography profile of cellular and intracellular stiffness was created by probing over a range of depths below the cell surface with an AFM nanoneedle. Differences between the softer external layer and the more rigid internal structure of corneocytes were revealed. The technique is capable of mapping structural properties of cells with high spatial resolutions and has potential use in the evaluation of clinical treatments or moisturization for skin care research.

Liu et al. have shown that the AFM nanoneedle is able to penetrate the cell membrane and directly measure the mechanical properties of cell nuclei in $\operatorname{situ}^{19}$. By characterizing the nuclear mechanics in living cells, they observed softened nuclei after isolation compared to intact cell nuclei. Furthermore, the stiffness of nuclei decreases in response to decreasing substrate stiffness, and cell nuclei becomes softer in cancer cells with higher metastatic potential. SUN-domain (Sad1p, UNC-84) and KASH-domain (Klarsicht, ANC-1, Syne Homology) proteins, which are often referred to as the linker of nucleoskeleton and cytoskeleton (LINC) complex, span the inner a
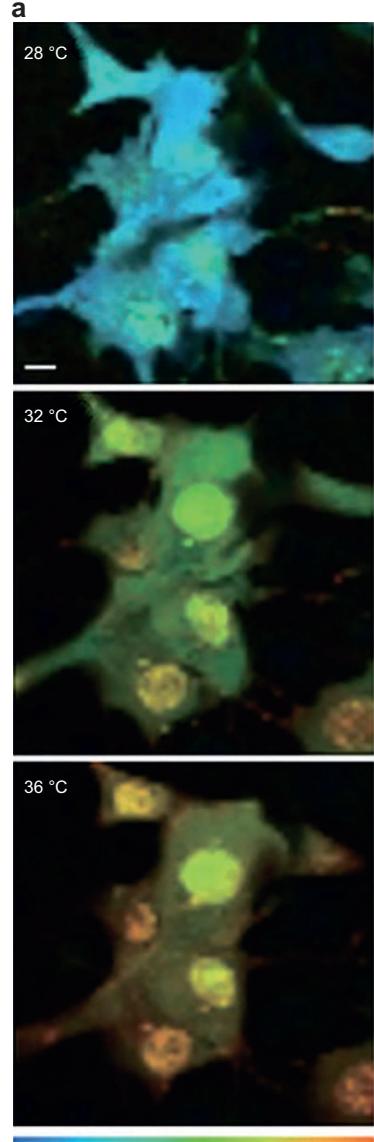

$28^{\circ} \mathrm{C}$

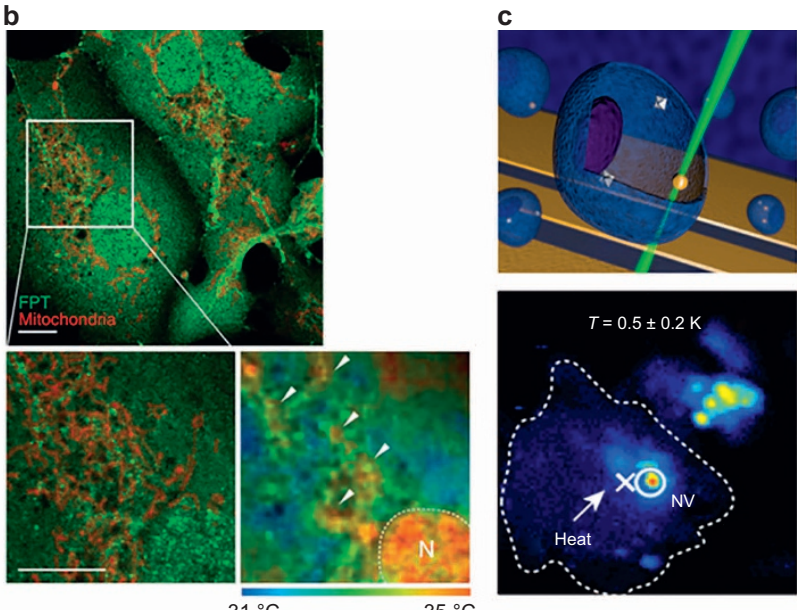

d
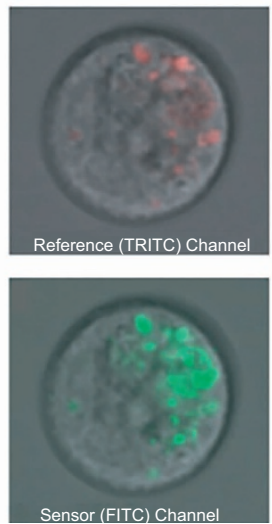

and outer nuclear membranes, linking the nucleoskeleton to the cytoskeleton $^{69}$. Direct probing of nuclear membranes can help improve understanding of the local heterogeneity of nuclear mechanics and the properties of the LINC complex as well as its roles in gene expression regulation under both physiological and pathological conditions. One can also envision the functionalization of AFM nanoneedles for probing focal traction forces of nuclei to understand nuclear mechanotransduction ${ }^{70}$.

CNT-modified AFM tips have been largely used for super-resolution AFM imaging because of the tips' high aspect ratio and mechanical robustness ${ }^{62,66}$. CNT nanopipettes and endoscopes, as discussed in the "Intracellular electrical measurement" section., have enabled intracellular sensing, particularly electrical measurements. However, CNT-modified AFM tips have not been used for intracellular force measurements or mechanical characterization. Because of their superb mechanical properties, CNTs are able to penetrate cell membranes well, and such AFM tips can be powerful tools for the measurement of the mechanical properties of intracellular structures.

\section{UNTETHERED INTRACELLULAR SENSING}

Untethered devices perform intracellular measurements without connections to extracellular instruments. These untethered sensors have a few common advantages: (1) the cell membrane remains intact because most untethered sensors are produced internally by cellular machineries or are introduced into the cell via passive delivery mechanisms, such as endocytosis; (2) cell activities are minimally disturbed because untethered sensors can move with cell structures during migration and mitosis; and (3) untethered sensors are suitable for long-term intracellular measurements.

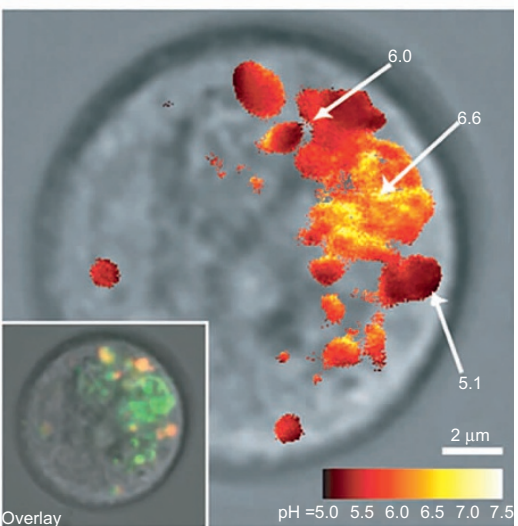

Figure 4 Nanoparticles for temperature and chemical sensing. (a) Fluorescent polymeric nanoparticles sensing temperature distribution within single cells. (b) Fluorescent nanoparticles reveal local heat production near mitochondria. (a and $\mathbf{b}$ ) reproduced with permission from Ref. 18. (c) Nanodiamonds sensing subcellular temperature gradients controlled by laser heating a gold nanoparticle. Reproduced with permission from Ref. 71. (d) $\mathrm{pH}$ sensors with core-shell architectures for ratiometric measurements. Reproduced with permission from Ref. 72 . 


\section{Nanoparticles as intracellular sensors}

Nanoparticle intracellular sensors include polymeric nanoparticles, silica nanoparticles, nanodiamonds, gold nanoparticles, and quantum dots ${ }^{73,74}$. Intracellular nanoparticle sensing is mainly based on fluorescence spectroscopy. Nanoparticle sensors can be either intrinsically fluorescent or conjugated with sensitive fluorescent dyes for sensing.

\section{Temperature sensing}

Nanoparticle luminescence thermometry was invented a few decades ago $^{75}$. Recently, its application has been extended to the measurement of intracellular temperature. Typically, the shapes, peak positions, lifetimes and intensities of nanoparticle emission bands are affected by temperature changes. For instance, the lattice of CdSe quantum dots becomes dilated at higher temperatures, which changes the interactions between the lattice and the electrons and leads to a red-shift in the emission spectrum ${ }^{76}$. Temperature change can be converted linearly from this spectrum shift. The first experimental evidence for inhomogeneous local thermogenesis in living cells was achieved by introducing $\mathrm{CdSe}$ quantum dots into $\mathrm{NIH} / 3 \mathrm{~T} 3$ murine fibroblast cells ${ }^{77}$. After $\mathrm{Ca}^{2+}$ shock (i.e., adding ionomycin calcium complex to elevate the intracellular concentration of $\left.\mathrm{Ca}^{2+}\right)$, the maximum temperature difference inside a living cell was measured to be $8{ }^{\circ} \mathrm{C}$. Although the temperature distribution among the organelles was not reported due to technical limitations, mitochondria probably would show the highest temperature because $\mathrm{Ca}^{2+}$ shock boosts heat production mainly by accelerating respiration ${ }^{78}$.

The inhomogeneous temperature distribution inside a cell has been confirmed using polymeric nanoparticles consisting of a thermosensitive unit, a hydrophilic unit, and a fluorescent unit ${ }^{18}$. In this study, fluorescence lifetime was used as a temperaturedependent variable. Single photon counting showed that the measurement had a temperature resolution of $0.18 \sim 0.58{ }^{\circ} \mathrm{C}$ with a spatial resolution of $200 \mathrm{~nm}$. In COS7 cells, the temperature of the cell nucleus was found to be significantly higher than that of the cytoplasm (Figure 4a). This behavior might result from the unique activities of the nucleus, such as DNA replication and transcription and RNA processing, or from its structural isolation by the nuclear membranes ${ }^{79}$. The average temperature difference was measured to be $0.96{ }^{\circ} \mathrm{C}$, and this temperature gap was dependent on the cell cycle. In the G1 phase, the nucleus was warmer by $0.70{ }^{\circ} \mathrm{C}$, whereas little difference was found in the S/G2 phases. The centrosome also showed a higher temperature of $0.75{ }^{\circ} \mathrm{C}$ possibly associated with its functions, such as the organization of microtubules and mitosis ${ }^{80}$. Heat production was also observed in mitochondria (Figure 4b). This heat release was accelerated when an uncoupling reagent stalled ATP synthesis, resulting in an average temperature increase of $1.02{ }^{\circ} \mathrm{C}$. A similar temperature distribution was also observed in HeLa cells.

Nanodiamonds are diamond nanocrystals with sizes of 4-5 nanometers. They have also been used to achieve ultra-high sensitivity in intracellular temperature measurements ${ }^{71}$. Nitrogenvacancy centers in nanodiamonds form spin-1 systems in the ground state and thermally induced lattice strains cause a change in the transition frequency. This mechanism can achieve an accuracy of $1.8 \mathrm{mK}$ with a spatial resolution of $200 \mathrm{~nm}$. By combining these nanodiamond thermometers with the laser heating of gold nanoparticles, subcellular temperature gradients have been monitored and controlled (Figure 4c). Human embryonic fibroblast WS1 cells were found to be still alive despite an approximately $10{ }^{\circ} \mathrm{C}$ increase at the location of a laser focus. However, because nanodiamonds were introduced into cells by nanowire-assisted delivery and only a small number were delivered, the temperature distributions inside living cells were not reported.

\section{Chemical sensing}

The combined use of sensitive fluorophores can significantly extend the application of nanoparticle sensors. Nanoparticles function as stable structural bases, whereas the sensing component is an analyte-sensitive dye molecule. Analytes include chemical properties, such as intracellular $\mathrm{pH}$, oxygen concentration, and ion concentrations (e.g., $\mathrm{Ca}^{2+}, \mathrm{Cu}^{2+}, \mathrm{Zn}^{2+}$ and $\left.\mathrm{H}_{2} \mathrm{PO}_{4}^{-}\right)^{81-83}$. Multiple fluorescent dye molecules are often integrated onto one particle to increase the brightness of a single probe.

A sensing dye and an analyte-insensitive reference dye can also be incorporated into the same particle to enable ratiometric measurement ${ }^{84,85}$. In addition to acting as a reference for measurement, the reference dye molecules also provide information about particle location and concentration throughout the cell. Compared to conventional free dye molecules, these hybrid nanosensors are independent of analyte concentration and sensor concentration, less sensitive to external disturbance, and more robust to changes in signal caused by photobleaching and leaching. One example using dual-emission nanoparticles was the investigation of calcium release from mitochondria during the mitochondrial permeability transition (MPT, opening an MPT pore across the inner mitochondrial membrane and causing cell death) ${ }^{86}$. After exposure to $m$-dinitrobenzene (m-DNB, a toxicant causing MPT), an increased cytosolic calcium level has been observed in two cell lines. Human SY5Y neuroblastoma (neuronal) cells showed significantly higher calcium release rates than those of C6 glioma (glial) cells. This finding confirms that the sensitivity or resistance to $\mathrm{m}$-DNB toxicity is associated with cell-specific propensity to undergo MPT. The work also provided evidence for why MPT is more likely to cause neurological diseases ${ }^{87}$.

Core-shell nanoparticle sensors have also been built in which a reference dye-rich core is coated with a thin-layer, sensing-dyerich silica shell ${ }^{88,89}$. The silica shell acts as a robust and biocompatible vehicle and protects the inner reference dyes from interactions with large molecules in the intracellular environment, such as organic quenchers and proteins, which may disturb the measurement. Core-shell sensors have been successfully used to measure $\mathrm{pH}$ in RBL mast cells, in which $\mathrm{pH}$ values varying from 6.5 in early endosomes to 5.0 in late endosomes/ lysosomes were measured (Figure $4 d)^{72}$. The acidification of the endocytic pathway mainly results from vacuolar-type $\mathrm{H}^{+}$-ATP hydrolases (V-ATPases) whose energy-driven active proton pumps cause proton accumulation inside endosomes. Different pumping rates or variations in the density of V-ATPases result in an increasingly acidic environment. Counter-ion and leak permeabilities also contribute to the increasing proton accumulation along the endocytic pathway ${ }^{90}$.

Although nanoparticles possess advantages in sensitivity, photostability and brightness, there are several challenges of using them for intracellular sensing rather than extracellular applications. First, nanoparticles introduced into living cells should be nontoxic. Although most published work has not observed adverse effects on cell viability or function, several reports ${ }^{91,92}$ have suggested that certain types of quantum dots may induce organelle damage and cell death. Others ${ }^{93,94}$ have indicated that toxicity may be a function of concentration and only high concentrations or repeated use of nanoparticles could be problematic. Second, the intracellular environment is complex, which may cause nanoparticles to be trapped in endocytic pathways, increasing the difficulty in targeting specific organelles. Finally, intracellular sensing requires transmembrane delivery of nanoparticles, which often requires complicated surface functionalization $^{95}$ or manipulation techniques. More details of the 

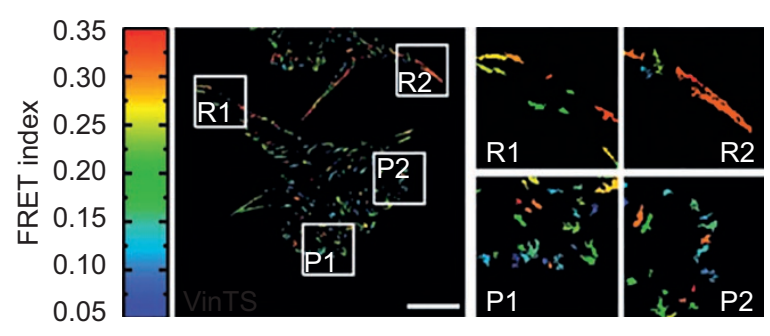

b

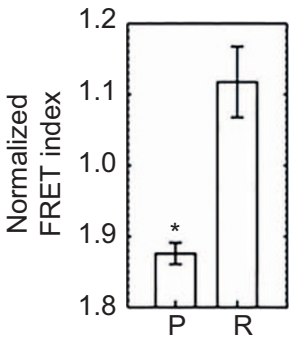

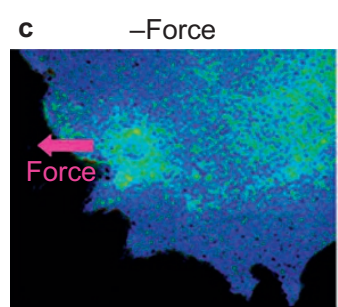

d

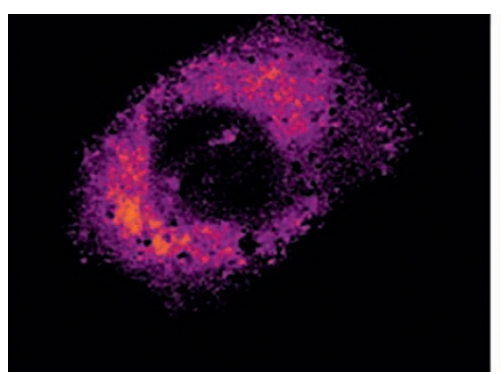

+Force (1 $\min )$
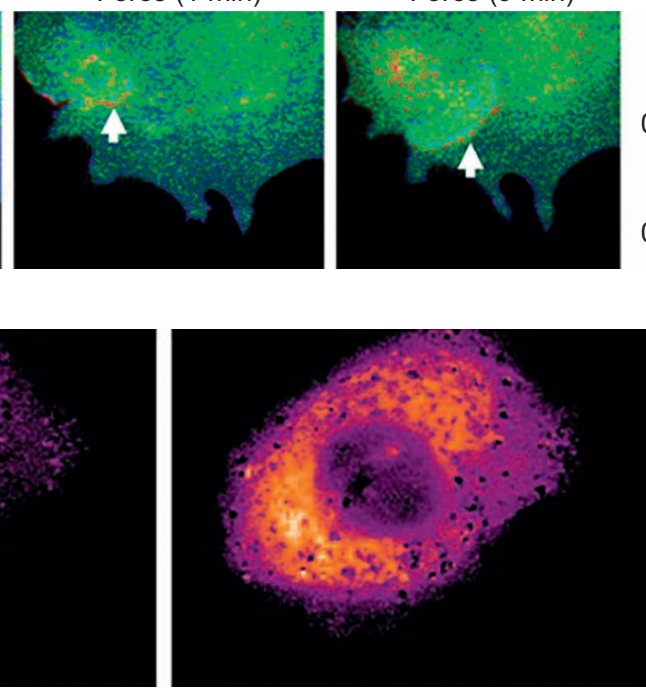

+Force (9 min)

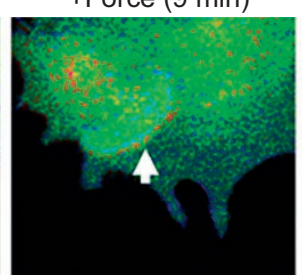

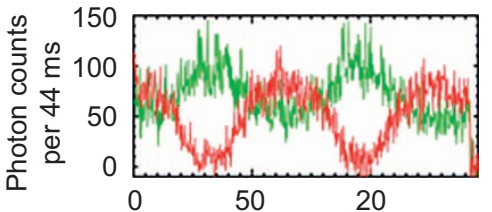

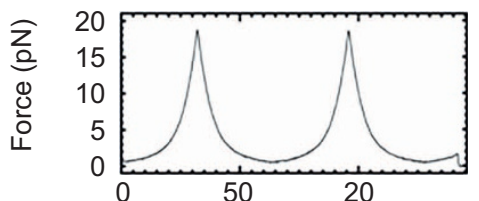

Src activity

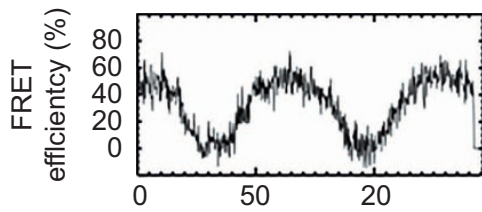

Time (s)

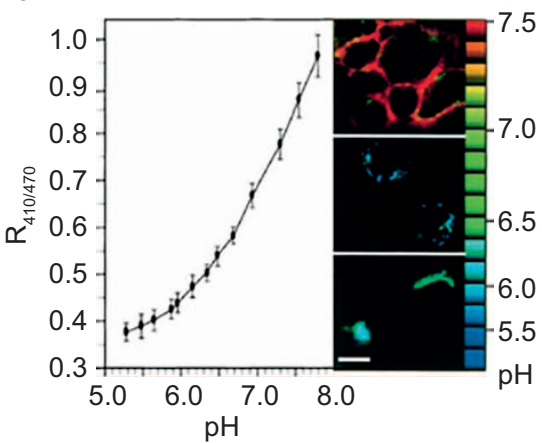

Figure 5 Fluorescent proteins and molecules for intracellular measurement. (a) Fluorescence resonance energy transfer (FRET) index of VinTS in migrating bovine aortic endothelial cells indicates high tension per vinculin near the protruding edges (P1 and P2) whereas force per vinculin is lower near retracting edges (R1 and R2). (b) Time traces show the inverse relationship between applied force and FRET efficiency. Fluorescence intensity time traces for donor (green) and acceptor (red). (a and b) reproduced with permission from Ref. 96. (c) FRET responses of a cell upon mechanical stimulation indicate a rapid distal Src activation and a slower wave propagation of Src activation. Reproduced with permission from Ref. 97. (d) Ratiometric fluorescence images of a cell during initial (left) and advanced (right) stages of irradiation; violet corresponds to lower viscosity and orange to higher viscosity. Reproduced with permission from Ref. 98 . (e) pH measurements with ratiometric pHluorin in HeLa cells. Left panel: calibration curve of 410/470-nm excitation ratios for HeLa cells. Top right: cell surface (pH 7.40). Middle right: endosomes ( $\mathrm{pH}$ 5.51). Bottom right: trans-Golgi network ( $\mathrm{pH}$ 6.21). Reproduced with permission from Ref. 99.

intracellular delivery of nanoparticles are discussed in the "Delivery and Extraction" section.

\section{Fluorescent proteins and molecules as intracellular sensors} Many cellular processes involve sensing and transducing elements that are distributed across plasma membranes, cytoskeletons, receptors on the nuclear envelope, and the proteins inside the nucleus. Various types of chemical and physical stimuli coordinately regulate and contribute to cellular events, including the dynamic response of cytoskeletal elements, motility and deformation of cellular organelles, localization, and translocation of signaling molecules as well as the ultimate gene expression ${ }^{100}$. However, population-based biochemical and immunostaining assays do not allow for direct study of the dynamics within living cells. Recent progress in bioengineered FPs, fluorescent molecules (FMs), and imaging technologies has greatly enhanced our ability to examine the physical and chemical parameters and biological activities in the intracellular domains of living cells noninvasively. FP/FM-based sensors require minimum effort to deliver into a cell and induce few perturbations to cell activities.

\section{Force sensing}

Genetically encoded and engineered to incorporate specific target proteins, FPs are produced by cellular machinery or introduced inside cells. FPs have been used to study how living cells sense and respond to internal or external mechanical loadings. The force-sensitive focal adhesion proteins vinculin and paxillin have been tagged with green fluorescent protein (GFP) to visualize the formation of focal complexes in response to local forces. Mechanical force is an essential signal for cells to regulate the strength of the adhesion force and mediate the focal complex development ${ }^{101}$. The application of the same vinculinfused FPs has shown that force-induced focal contact functions as a mechanosensor ${ }^{102}$. When combined with fluorescence resonance energy transfer (FRET), vinculin-fused FPs have been calibrated and used as "tension sensors" to quantify the force distribution inside a cell. The forces across the protein modulate the distance and orientation between the donor and acceptor fluorophores and, thus, alter the intensity of FRET (Figure 5a and b) ${ }^{96}$. By modifying the FRET-based vinculin tension sensor to link the cytoplasmic domains of the endothelial cell-cell junctional VEcadherin and PECAM-1, studies have shown that fluidic shear 
forces increase the tension across PECAM-1, which triggers active cytoskeletal remodeling that is likely associated with decreased tension on VE-cadherin ${ }^{103}$.

\section{Mechanotransduction}

FP-based biosensors have also been used to monitor the mechanotransduction cascade within a cell. Cdc42 activity in single cells has been visualized by FRET of Cdc42-fused GFP and shown to be activated by the surrounding fluid shear stress in a polarized manner following the direction of flow, as a consequence of integrins binding to the extracellular matrix ${ }^{104}$. Flow-mediated shear stress applied to bovine aortic endothelial cells has been shown to cause a successive increase of NF- $\kappa B$-regulated gene activation, as indicated by decreased FRET efficiency of the I $\mathrm{B} \alpha$ EYFP/ECFPrelA complex ${ }^{105}$. Local mechanical stimulation introduced by optical trapped fibronectin-coated beads adhering to the human umbilical vein endothelial cells (HUVECs) has been shown to activate the Src in a dynamic process via the cytoskeleton (Figure $5 \mathrm{c})^{97}$. The activated Src causes phosphorylation and conformational change of the FRET donor and acceptor. Therefore, the FRET level of this Src-specific FP-based biosensor could indicate the mechano-activation status of Src.

The shape and motion of the subcellular organelles can also provide insight into the global dynamics of live cellular processes. Fluorescent biosensors that are engineered to localize at specific organelles can serve as markers for those organelles, thus allowing the deformation and movement of the organelles to be observed while live cells are subject to different mechanical stimuli. GFP conjugated to nuclear Lamin A was used to label the nuclear envelope for the study of nuclear structure and property changes during micropipette aspiration of nuclei. The loss of emerin has been shown to be the likely cause of the less deformable GFPlabeled nuclear envelope under mechanical force, suggesting a link between the altered nuclear mechanics and the pathological conditions of Emery-Dreifuss muscular dystrophy patients ${ }^{106}$. FibGFP has been applied as a fiduciary marker for intranuclear rheology in HeLa, HUVEC, and osteosarcoma cells, allowing visualization of force-induced subnuclear movements. Under adequate mechanical stimulation, the nucleus plays a mechanosensing role and its repositioning or architectural change could lead to altered chromatin organization resulting in adaptive gene expression ${ }^{107}$.

FRET is commonly used in conjunction with FPs to study molecular dynamics in cell mechanotransduction. Additionally, several other imaging technologies are used, such as fluorescence lifetime imaging microscopy (FLIM), fluorescence recovery after photobleaching (FRAP), and fluorescence loss in photobleaching (FLIP). For example, the intracellular viscosity plays an important role in determining the rate of cytoplasmic and intercompartmental traffic of the signaling molecules and proteins. Combined with FLIP technology, fluorescent molecular rotors that exhibit different fluorescent emission lifetimes in different ambient viscosities have become a practical method for measuring cellular microviscosity in real time ${ }^{98,108,109}$. A dramatic increase in intracellular viscosity during photoinduced cell death has been demonstrated using a new type of ratiometric fluorescent molecular rotor that is capable of mapping the microviscosity within live cells (Figure $5 \mathrm{~d})^{98}$. The mechanobiology applications of FPs combined with other imaging technologies are reviewed in detail elsewhere ${ }^{100,110}$.

\section{Chemical and temperature sensing}

GFP-based sensors can be applied to measure intracellular $\mathrm{pH}$ levels. There are many GFP mutants that have fluorescence and absorbance properties that are strongly $\mathrm{pH}$ dependent in living cells. This characteristic has been used for intracellular $\mathrm{pH}$ measurement within the cytoplasm and subcellular organelles (Figure $5 \mathrm{e})^{99,111}$. Recently, a highly chloride-sensitive GFP variant has been found to be capable of measuring the chloride and $\mathrm{pH}$ level simultaneously inside various intracellular compartments ${ }^{112}$. Moreover, spatially resolved temperature measurements inside living cells have been achieved using either FPs or FMs. These biosensors exploited reversible and non-invasive temperaturedependent characteristics, such as the blinking relaxation time of the GFP ${ }^{113}$, the fluorescence polarization anisotropy of the GFP ${ }^{114}$ and the hairpin structure and FRET signaling mechanism of the L-DNA molecular beacon ${ }^{115}$. These nanoscale thermometers are
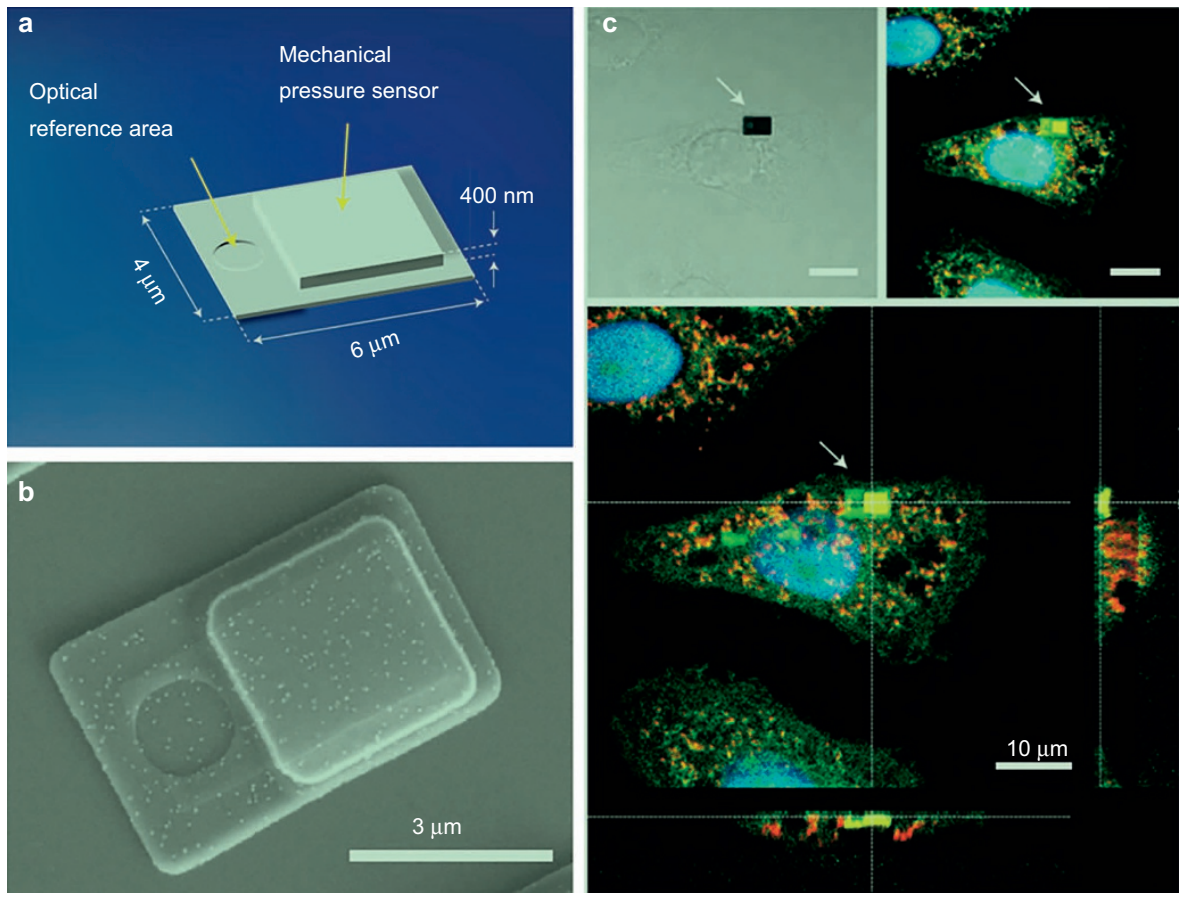

Figure 6 MEMS pressure sensor for intracellular pressure measurement. Reproduced with permission from Ref. 116. (a) Sensor schematic. (b) SEM image of a fabricated device. (c) MEMS pressure sensor internalized into the cytoplasm of a HeLa cell. Top left: transmitted visible light image. Top right: overlay of confocal images. Bottom: orthogonal projection of confocal images showing that the device is inside the cell. 
suitable for studies in which heat plays a significant role, for instance, cancer therapeutics.

\section{Untethered MEMS sensors}

MEMS sensors, typically tethered to external instruments, have been widely applied for measuring the mechanical properties of whole cells ${ }^{117-119}$. Recently, efforts have been made to develop untethered MEMS devices to perform measurements inside single cells $^{120,121}$. These MEMS devices have been delivered into single HeLa cells to measure intracellular pressure changes (Figure 6) ${ }^{116}$. The untethered silicon devices are fabricated with two membranes separated by a vacuum gap and an optical reference area. Once internalized into a cell, the intracellular pressure change deflects the device membrane, which changes the gap size and alters the intensity of reflected light at the center of the membrane. The optical reference area is used for focusing purposes. Because the internalized silicon device represents only $0.2 \%$ of the total volume of a HeLa cell, the MEMS device was not found to affect cell viability. Compared with other external force/ pressure sensors or tethered probes, such as modified AFM tips, the untethered MEMS device can directly measure intracellular pressure while the cell membrane integrity remains unchanged. The experimental data measured by the untethered MEMS pressure sensors confirm that extracellular pressure is transmitted through the cytosol to the inner compartments, proving that the intracellular transmission of fluid pressure follows Pascal's law. The intracellular pressure measurement also shows that intracellular pressure remains practically unaltered inside the cytosol and vacuoles during an osmotic shock, suggesting that these cells are able to prevent the inward flow of water across their membranes. The work confirms that MEMS devices can be internalized into a single cell to perform intracellular measurements. Although only pressure measurements were made, further development of untethered MEMS devices can potentially enable the measurement of other intracellular physical and chemical quantities.

\section{INTRACELLULAR MANIPULATION}

\section{Delivery and extraction}

Performing intracellular measurement often requires the delivery of foreign materials into cells. Microinjection is a widely used technique for actively delivering membrane-impermeable materials into a cell. It is a mechanical process involving the use of a sharp micropipette $(0.5 \sim 5 \mu \mathrm{m})$ to penetrate the cell membrane for material delivery ${ }^{122}$. Although glass micropipettes are widely used for microinjection, concerns have been raised over cell damage, and glass tips are easily broken. Hence, several groups have reported the use of CNTs as microinjection tips. The robustness of CNT tips has been demonstrated via a buckling test ${ }^{44}$. Although the small tip size makes CNT nanopipettes less invasive to cells, delivering materials through them requires very high pressure without which only a small volume of liquid preloaded in the CNT tip can be delivered into the cell via passive diffusion ${ }^{56}$.

Because of their capability of accessing the interior of living cells, AFM nanoneedles have also been adopted for intracellular delivery of materials via surface functionalization. A common strategy for functionalizing silicon nanoneedles is to form selfassembled monolayers of alkylsilanes through the silane coupling reaction. Several groups have demonstrated the immobilization of proteins and DNA on the surface of AFM nanoneedles and achieved successful intracellular delivery ${ }^{65,123-126}$. For instance, Nakamura et al. have demonstrated the direct delivery of GFPtagged DNA into the nuclei of individual cells using an AFM nanoneedle and achieved a high gene expression rate of $70 \%$ (vs.
$10 \%$ for microinjection on $\mathrm{MSCs})^{123}$. To reduce nonspecific adsorption of cargo onto nanoneedles, Bertozzi et al. and Yu et al. have developed a method of controlled release of $\operatorname{cargo}^{127,128}$, which utilizes the reductive cleavage of the disulfide bond. Using this bonding-releasing strategy, AFM CNT tips are preloaded with streptavidin-coated quantum dots via a linker molecule ${ }^{127}$. The linker molecule contains a pyrene moiety bonding to CNT surfaces, a biotin moiety that can bond to the cargo (i.e., streptavidin QDots), and a disulfide bond to connect the two function groups. The disulfide bond is stable in the relatively oxidizing extracellular environment, while the bond is cleaved once exposed to the reducing intracellular environment in which oxidized elements tend to be reduced. Thus, the foreign cargo is released into the cell.

AFM-tip-based intracellular delivery has low throughput, and cargo loaded on the surface of the AFM tip is limited. Therefore, arrays of vertical nanoprobes, particularly silicon nanowires, have been developed to deliver a variety of materials into many cell types ${ }^{39}$. Foreign materials, such as plasmid DNA, siRNA, IgGs, QDots, rhodamine-labeled peptides, and recombinant FPs, have been pre-coated on the silicon nanowires. Both cell lines and primary cells have been cultured on the sharp vertical silicon nanowires that are able to penetrate into cells ${ }^{129,130}$. Similarly to nanowire MEAs discussed in the "Intracellular electrical measurement" section., this vertical delivery platform is limited to targeting specific cells. Although nanowire-induced membrane damage appears minimal, their effects on cell functions remain unknown. Studies have shown that long-term culturing on vertical silicon nanowire platforms could negatively affect cell proliferation ${ }^{131}$, adhesion, and migration ${ }^{132}$.

Other physical approaches for intracellular delivery include electroporation ${ }^{133,134}$, which uses electrostatic forces to disrupt the cell membrane; sonoporation ${ }^{135,136}$, which generates acoustic pressure to trigger cavitation bubbles to induce membrane permeability; and optoporation ${ }^{137,138}$, which utilizes nonlinear optical absorption caused by a laser pulse to open cell membranes. Since electroporation was developed for gene transfer in early $1980 s^{139}$, it has been widely used to introduce foreign materials into cells. In recent years, there have been an increasing number of studies utilizing microfluidic devices for cell electroporation ${ }^{140}$. The evolution and recent advances in electroporation techniques have been reviewed extensively elsewhere ${ }^{141,142}$. To perform intracellular delivery of large cargos, such as bacteria, enzymes, antibodies and nanoparticles, Wu et al. have developed a biophotonic laser-assisted surgery tool (BLAST) system that can deliver large elements into 100,000 cells in one minute ${ }^{143}$. The BLAST system generates an array of microcavitation bubbles that explode in response to laser pulsing, making pores in adjacent cell membranes. Foreign materials are driven through the bubble-induced pores. The platform has been used to investigate the intracellular pathogenesis of Francisella novicida. A new pathogenic role of the ig/C gene has been found with the BLAST platform ${ }^{144}$.

In addition to physical approaches, foreign materials can also enter a cell via endocytosis, in which cells intake foreign materials by engulfing them with membrane-bounded vesicles. Endocytosis has two major pathways, phagocytosis and pinocytosis, the latter of which can be further classified into macropinocytosis, clathrin-mediated and caveolae-mediated endocytosis ${ }^{145}$. Phagocytosis often occurs in macrophages to internalize large particles through phagosomes or food vacuoles. Pinocytosis exists in almost all cell types to uptake relatively small particles $(<150 \mathrm{~nm})$. Objects taken up through clathrin-mediated endocytosis are approximately $100 \mathrm{~nm}$, and objects taken up through caveolae-mediated endocytosis are $60-80 \mathrm{~nm}^{146}$. Endocytosis is a 
natural process that passively internalizes foreign materials. The material uptake rate, or delivery rate, mostly depends on the material size ${ }^{147}$, shape ${ }^{148}$, and physical and chemical properties of the surface ${ }^{149}$. Nanoparticles of $20-50 \mathrm{~nm}$ are taken up more easily by cells than the smaller or larger particles ${ }^{150-152}$. The optimal size of internalized nanoparticles also falls in the size range of typical viruses, suggesting broad implications for biomaterial design principles that evolved from natural selection $^{147}$. Experiments have also demonstrated that shape is another important factor for determining the uptake rate ${ }^{153,154}$. Nanoparticles with spherical shapes have higher uptake rates in HeLa cells than those with cylindrical, cubic, or rod shapes ${ }^{152,155}$. Nanorods with higher aspect ratios have a lower uptake rate ${ }^{155}$.

Because the cell membrane typically possesses negative charges, cationic nanoparticles (i.e., positively charged nanoparticles), compared with anionic or neural particles, are more likely to bind to the cell membrane, resulting in a higher uptake/ delivery rate ${ }^{156,157}$. To achieve a high uptake rates, untethered nanoparticles can also be coupled with cell-penetrating peptides, such as oligonucleotides ${ }^{158}$, interleukin-13 peptide $^{159}$, pentapeptide $^{160}$, and amphipathic palmitoylated peptide ${ }^{161}$. Endocytosis for delivering untethered sensors into cells is mostly used for cytosolic measurements. However, when attempting to deliver sensors that target specific organelles, such as lysosomes ${ }^{162}$, the endoplasmic reticulum ${ }^{163}$, nuclei $^{164}$, and mitochondria ${ }^{165}$, untethered cargos are often trapped in endosomes or liposomes during the endocytosis process ${ }^{160,166}$. Additionally, delivering large amounts of foreign materials via endocytosis can have

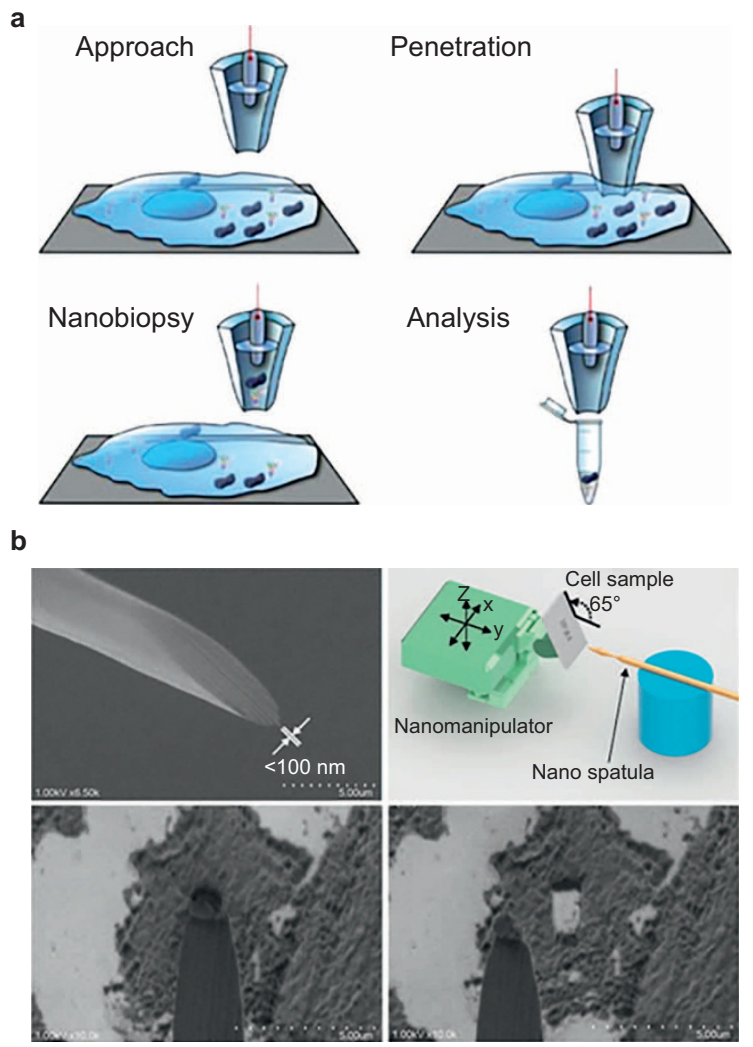

Figure 7 Intracellular biopsy. (a) Cell membrane is penetrated, and cytoplasmic material is extracted via electrowetting. Adapted with permission from Ref. 170. (b) Extraction of a single chromatin from within a cell nucleus. Reproduced with permission from Ref. 171. significant negative effects on regular transmembrane traffic mechanisms ${ }^{167-169}$.

Intracellular biopsy refers to the operation of extracting intracellular structures or organelles from within a cell. Early intracellular biopsy included the enucleation of large reproductive cells such as oocytes by using glass micropipettes to remove oocyte nucleus, which is a key step for cloning of mammalian animals ${ }^{172,173}$. It has recently been demonstrated that smaller organelles, such as mitochondria, can also be extracted out of a cell (Figure $7 a)^{170}$. A pulled glass nanopipette, together with the electrowetting technique, was used to extract small subpopulations of mitochondria from living cells with minimal disruption of the cellular milieu. After extraction, the mutant mitochondrial genomes were then sequenced. The technology enables the quantitative assessment of mitochondrial mutation rates in single cells, which is an important step in understanding why and how cellular degenerative mutations gradually build up over time to cause cellular dysfunction and death.

Under scanning electron microscopy (SEM) imaging, subnuclear biopsy has been reported in which a single chromatin was extracted from within a cell nucleus (Figure $7 \mathrm{~b})^{171}$. In this work, the nanodissection of DNA from thin sections of cells was performed via high precision nanomanipulation inside an SEM. Correlative imaging using fluorescence and SEM images was used to identify targets for a nanospatula to extract. The ability to dissect and identify gene loci occupying a shared site in a single subnuclear structure was demonstrated. The technique was applied to the nanodissection of DNA in the vicinity of a single promyelocytic leukemia nuclear body (PML NB), and revealed novel loci from several chromosomes that were confirmed to associate at PML NBs with statistical significance in a cell population.

\section{Translocation}

Moving an object inside a cell (i.e., translocation) must cause minimal disturbance to cell functions and activities. The intracellular objects to translocate include endogenous organelles and foreign untethered materials, which are manipulated remotely via techniques such as optical trapping and magnetic tweezers. Optical trapping uses a focused laser beam to produce an attractive or repulsive force depending on the refractive index mismatch to physically hold and move micro/nano-objects. Optical tweezers can be used to move either foreign nanoparticles or directly manipulate intracellular organelles ${ }^{174}$. In early 1989 , it was shown that infrared laser traps can be used to apply controlled forces to study the mechanical properties of the cytoplasm of plant cells ${ }^{175}$. Optical tweezers have also been used to perform internal cell surgery by changing the locations of relatively large organelles, such as chloroplasts and nuclei. In direct manipulation of organelles or subcellular structures, optical tweezers do not require a foreign end-effector that is physically present in the cell, and damage to the cell can be minimal ${ }^{176}$. This technique is limited in force generation (pN levels), and increasing laser power for larger force generation has the risk of laserinduced cell damage. Improvements are under development for minimizing photodamage by using specially shaped optical tweezers $^{177}$.

Magnetic nanoparticles, after introduced into cells, can be moved by magnetic forces generated by controlled magnetic fields. Magnetic tweezers have been used on cells for characterizing cellular elasticity and cytoplasmic viscosity ${ }^{178,179}$. Because cells do not contain magnetic structures, the force is specifically applied to the internalized magnetic particles. Magnetic tweezers have also been used for manipulating intracellular structures such as chromatin ${ }^{180}$ and phagosomes ${ }^{181}$. Compared with optical tweezers, the forces generated by magnetic fields are larger, 
ranging from a few piconewtons ${ }^{182}$ to several nanonewtons ${ }^{183}$. Although most magnetic tweezers reported in the literature apply forces in one direction only, there are a growing number of systems that allow 2D and 3D manipulation ${ }^{184,185}$.

Other remote manipulation systems, such as acoustic tweezers, have also started to show potential for intracellular manipulation. Acoustic systems have recently been developed for controlled intracellular drug delivery ${ }^{186}$. The system uses acoustic droplet vaporization to release perfluoropentane droplets in single droplet-loaded macrophages by insonation with single threecycle ultrasound pulses. Another study has reported an ultrasound tweezing cytometry utilizing ultrasound pulses to actuate functionalized lipid microbubbles that are covalently attached to single cells, to exert mechanical forces in the $\mathrm{pN}-\mathrm{nN}$ range ${ }^{187}$. The ultrasonic excitation of microbubbles could elicit a rapid and sustained reactive intracellular cytoskeleton contractile force increase in different adherent mechanosensitive cells.

\section{SUMMARY AND OUTLOOK}

Emerging microsystems and nanoengineering technologies have enabled recent advancements in the direct measurement of intracellular properties, although the development of micro- and nanoengineered tools for intracellular manipulation and measurement is still preliminary. Table 1 summarizes existing measurement techniques. Due to their small sizes and unique electrical properties, nanowires and nanotubes have been used to build tethered probes for intracellular electrical measurement. AFM tips, modified via FIB or via direct assembly/growth of nanowires or nanotubes, have been used to quantify intracellular mechanical characteristics. FPs involved in mechanotransduction pathways have also been used to measure intracellular tensions/forces and viscosities. Untethered nanoparticles and MEMS sensors, after being introduced into cells using manipulation techniques, have been used to measure other physical properties (e.g., temperature, pressure) and chemical properties (e.g., $\mathrm{pH}, \mathrm{Ca}^{2+}$ concentration) inside a cell. By combining untethered sensors with tethered probes (e.g., $\mathrm{SiO}_{2}$ nanowires), intracellular activities have been transformed into photonic signals and measured via optical single-cell endoscopes.

A number of interesting discoveries have been made with these new microsystems and nanoengineered devices. Intracellular electrical measurement by kinked nanowire FET has demonstrated

Table 1 Micro/nano devices for intracellular measurements

\begin{tabular}{|c|c|c|c|}
\hline Measurement & Technique & Description & References \\
\hline \multirow[t]{4}{*}{ Electrical properties } & 3D kinked silicon nanowire & $\begin{array}{l}\text { NanoFET built on kinked nanowire; phospholipid bilayer coated; sensitivity: } \\
4 \sim 8 \mu \mathrm{S} / \mathrm{N} \text { for conductance measurement; capable of } \mathrm{pH} \text { measurement with a } \\
58 \mathrm{mV} / \mathrm{pH} \text { sensitivity }\end{array}$ & $20,28,29$ \\
\hline & Branched nanoFET & Hollow $\mathrm{SiO}_{2}$ structure; $5 \mathrm{~nm}$ probe size with controlled taper tip & 31,32 \\
\hline & Multielectrode arrays & $\begin{array}{l}\text { Parallel sensing; higher throughput; unknown disturbance to cell activities; } \\
\text { unable to control individual insertion depth }\end{array}$ & $33,36,37,38$ \\
\hline & Carbon nanotube & $\begin{array}{l}\text { High tensile strength and elastic modulus; high electric current density; } \\
\text { 100 200 nm tip size }\end{array}$ & $34,44,45,46,51$ \\
\hline \multirow[t]{4}{*}{ Mechanical properties } & Modified AFM tip & $\begin{array}{l}\text { Fabricated via FIB or direct growth/assembly of nanowires on AFM tips; } \\
\text { capable of measuring nuclear mechanics and mapping intracellular stiffness; } \\
30 \sim 180 \mathrm{~nm} \text { tip diameter; } 0.5 \sim 6 \mu \mathrm{m} \text { tip height }\end{array}$ & $19,34,48,60,61,62$ \\
\hline & Vinculin-fused fluorescent protein (FP) & $\begin{array}{l}\text { Force sensitive focal adhesion proteins tagged with GFP used to visualize the } \\
\text { formation of local complex in response to local forces }\end{array}$ & 96 \\
\hline & Cdc42/Src-specific FP & $\begin{array}{l}\text { Local mechanical stimulation induces changes in the FRET level of Cdc42/ } \\
\text { Src-specific fluorescent signal }\end{array}$ & 97,104 \\
\hline & Lamin-A/Fib GFP & $\begin{array}{l}\text { GFPs conjugated to nuclear Lamin-A or Fib reveal the shape and motion } \\
\text { changes of nucleus in response to mechanical stimulation }\end{array}$ & 107 \\
\hline \multirow[t]{4}{*}{ Temperature } & CdSe quantum dots & $\begin{array}{l}\text { Temperature changes convert to spectrum shift; first experimental } \\
\text { demonstration of heterogeneous intracellular temperature }\end{array}$ & 76,77 \\
\hline & Polymetric nanoparticles & $\begin{array}{l}\text { Consist of a thermosensitive unit, a hydrophilic unit, and a fluorescent unit; } \\
0.18 \sim 0.58{ }^{\circ} \mathrm{C} \text { resolution; } 0.96{ }^{\circ} \mathrm{C} \text { average temperature variance in COS7 cells }\end{array}$ & 18 \\
\hline & Nanodiamond & $\begin{array}{l}\text { Ultrahigh } 1.8 \mathrm{mK} \text { resolution; thermally induced lattice strains cause the } \\
\text { changes in transition frequency }\end{array}$ & 46,71 \\
\hline & GFP & $\begin{array}{l}\text { Intracellular temperature variations cause GFP characteristic changes in } \\
\text { blinking relaxation time or polarization anisotropy }\end{array}$ & $113,114,115$ \\
\hline \multirow[t]{3}{*}{$\begin{array}{l}\text { Chemical sensing } \\
\text { (e.g., } \mathrm{pH}, \mathrm{Ca}^{2+}, \mathrm{Cu}^{2+}, \mathrm{Cl}^{-} \text {) }\end{array}$} & Dual-emission nanoparticle & $\begin{array}{l}\text { Incorporation of a sensing dye and analyte insensitive reference dye enables } \\
\text { ratio metric measurement }\end{array}$ & 84,85 \\
\hline & Core-shell nanoparticle & $\begin{array}{l}\text { A reference-dye-rich core coated with a thin layer of sensing-dye-rich silica } \\
\text { shell; measured endosome } \mathrm{pH} \text { varying from } 5.0 \text { to } 6.5\end{array}$ & 88,89 \\
\hline & GFP & $\begin{array}{l}\text { Fluorescence and absorbance properties of mutant GFP reflect intracellular } \\
\mathrm{pH} \text { level }\end{array}$ & $99,111,112$ \\
\hline Pressure & MEMS sensor & $\begin{array}{l}\text { Intracellular pressure deflects device membrane and alters the intensity of } \\
\text { reflected light; introduced into cell via lipofection; device size: } 4 \times 6 \times 0.4 \mu \mathrm{m}\end{array}$ & 116 \\
\hline Optical measurement & $\mathrm{SiO}_{2}$ nanowire & $\begin{array}{l}\text { Works as either a light source for imaging or a spectrometer to collect optical } \\
\text { signal; can be coupled with untethered nanoparticles to measure intracellular } \\
\text { pH or temperature; } 100 \sim 250 \mathrm{~nm} \text { tip size }\end{array}$ & 35 \\
\hline
\end{tabular}


five characteristic phases of a cardiac intracellular potential, including (a) resting state, (b) rapid depolarization, (c) plateau, (d) rapid repolarization, and (e) hyperpolarization. Additionally, a sharp transient peak and a notch that is possibly associated with inward sodium and outward potassium currents has also been observed $^{28}$. Intracellular electrical measurement by a CNT endoscope has revealed as light membrane hyperpolarization in the mitochondria following the calcium elevation, which suggests that mitochondria are able to sequester $\mathrm{Ca}^{2+}$ from the surroundings forcing them to intensively generate additional energy ${ }^{34}$. Intracellular electrical measurement by carbon nanopipettes has confirmed that an increase in the extracellular $\mathrm{K}^{+}$concentration can produce a significant increase in the membrane potentials (i.e., a higher depolarization) ${ }^{45}$.

Intracellular mechanical characterization by modified AFM tips has revealed nuclear softening in the highly metastatic bladder cancer cell line T24 when compared with its less metastatic counterpart RT4 cell line ${ }^{19}$. Intracellular temperature measurements by quantum dots has revealed local heterogeneous temperature progression ${ }^{77}$. Measurements by quantum dots have also shown that the shape of HeLa cells remains essentially unchanged when the intracellular temperature is raised to $50{ }^{\circ} \mathrm{C}$, whereas measurement by $\mathrm{NaYF}_{4}: \mathrm{Er}^{3+}, \mathrm{Yb}^{3+}$ nanoparticles has revealed a small fragment of the HeLa cell membrane with an internal temperature of $45^{\circ} \mathrm{C}^{188}$. Intracellular temperature measurements by nanodiamonds have shown that cells remain alive when the local temperature increases by $10{ }^{\circ} \mathrm{C}^{71}$.

Intracellular $\mathrm{pH}$ measurement by core-shell nanoparticles has shown that the intracellular $\mathrm{pH}$ varies from 6.5 in early endosomes to 5.0 in late endosomes/lysosomes ${ }^{72}$. Intracellular $\mathrm{pH}$ measurement by a pH-sensitive mutant GFP has shown that the $\mathrm{pH}$ level varies in different subcellular organelles, such as endosomes and the trans-Golgi network ${ }^{99}$. Intracellular pressure measurement by MEMS devices has demonstrated that intracellular pressure remains unaltered inside the cytosol and vacuoles during osmotic shock, supporting the fact that the cells prevent the inward flow of water across their membranes ${ }^{116}$. Intracellular nuclear biopsy has proven that genetic materials have preferred locations and are well organized inside a cell nucleus ${ }^{171}$.

Existing intracellular work started with manipulating and measuring large organelles, such as cell nuclei, and then moved onto targeting smaller organelles, such as mitochondria. Many intracellular properties (e.g., $\mathrm{pH}$ and temperature) in existing studies have been measured in the cytoplasm. Future micro- and nanoengineered tools will become even finer in size and more powerful in function to monitor real-time changes of suborganelle signals, such as $\mathrm{pH}$ and temperature changes during ATP synthesis in mitochondria and calcium storage variations in the nuclear membrane, reticulum, and Golgi apparatus ${ }^{189,190}$.

New materials, such as graphene, may possibly help in the development of more accurate and sensitive measurement tools $^{191}$. Graphene FETs have been developed to monitor action potentials of cardiomyocytes extracellularly ${ }^{192,193}$. Graphenebased sensors might be developed and delivered into single cells for intracellular electrical measurements. In addition to new materials, emerging imaging techniques might also significantly accelerate the advancement of intracellular measurement and manipulation capabilities. Studies using near-field imaging enabled by optical nanowires have demonstrated the ability to accurately detect fluorescent signals with higher resolutions ${ }^{35}$. These new imaging capabilities might enhance the observation and measurement of subcellular and suborganelle signal changes.

Presently, intracellular measurement and manipulation is manually conducted. Automation technologies can be developed to help minimize human errors and skill inconsistency ${ }^{194}$. Automation would allow researchers to more easily position tethered devices or more accurately move untethered sensors inside a cell. In manual microinjection, for example, the number of injected cells is limited to several or tens of cells ${ }^{195}$. To increase throughput, robotic systems have shown the injection of over 1,000 cells (e.g., HL-1 cells) within one hour ${ }^{196}$. The significantly higher throughput enabled quantitative characterization of gap junction function on a large cell population, which might enable the large-scale screening of drugs for rescuing abnormal cell-cell communications in cardiomyocytes. To improve the performance of magnetic or optical tweezers, automated functions are under development to increase the spatial resolution and accuracy for the manipulation of single cells ${ }^{197,198}$. These technologies have direct relevance and might be expanded to enhance intracellular manipulation and measurement.

Compared to measurements in single cells, the direct measurement and manipulation of subcellular structures and organelles remains largely underexplored. In the pursuit of better understanding of intracellular properties, the development of new microsystems and nanoengineered techniques would transform cell biology by enabling intracellular measurement and manipulation. These new tools would enable researchers to directly interrogate intracellular structures, explore the environment inside a cell, and observe and measure intracellular processes and activities with high spatial and temporal resolutions. The exciting era of intracellular measurement and manipulation has just begun.

\section{COMPETING INTERESTS}

The authors declare no conflict of interest.

\section{REFERENCES}

1 Lowell BB, Spiegelman BM. Towards a molecular understanding of adaptive thermogenesis. Nature 2000; 404: 652-660.

2 Patel D, Franklin KA. Temperature-regulation of plant architecture. Plant Signaling \& Behavior 2009; 4: 577-579.

3 Jiang $\mathrm{H}$, Sun SX. Cellular pressure and volume regulation and implications for cell mechanics. Biophysical Journal 2013; 105: 609-619.

4 Ehrlich PJ, Lanyon LE. Mechanical strain and bone cell function: A review. Osteoporosis International 2002; 13: 688-700.

5 Kim D-H, Wong PK, Park J et al. Microengineered platforms for cell mechanobiology. Annual Review of Biomedical Engineering 2009; 11: 203-233.

6 Moody W. Effects of intracellular $\mathrm{H}+$ on the electrical properties of excitable cells. Annual Review of Neuroscience 1984; 7: 257-278.

7 Waddell WJ, Bates RG. Intracellular pH. Physiological Reviews 1969; 49: 285-329.

8 Silver IA, Deas J, Erecińska M. Ion homeostasis in brain cells: Differences in intracellular ion responses to energy limitation between cultured neurons and glial cells. Neuroscience 1997; 78: 589-601.

9 Kinashi T. Intracellular signalling controlling integrin activation in lymphocytes. Nature Reviews Immunology 2005; 5: 546-559.

10 Severs NJ, Coppen SR, Dupont E et al. Gap junction alterations in human cardiac disease. Cardiovascular Research 2004; 62: 368-377.

11 Zipes DP, Wellens HJJ. Sudden cardiac death. Circulation 1998; 98: 2334-2351.

12 Heron M. Deaths: Leading causes for 2010. National Vital Statistics Reports 2013; 62: 1-96.

13 Lagadic-Gossmann D, Huc L, Lecureur V. Alterations of intracellular pH homeostasis in apoptosis: Origins and roles. Cell Death and Differentiation 2004; 11 : 953-961.

14 Gerweck LE, Seetharaman K. Cellular pH gradient in tumor versus normal tissue: Potential exploitation for the treatment of cancer. Cancer Research 1996; 56: 1194-1198.

15 Thomas RC. Intracellular $\mathrm{pH}$ of snail neurones measured with a new $\mathrm{pH}$ sensitive glass mirco-electrode. The Journal of Physiology 1974; 238: 159-180.

16 Kelly SM, Macklem PT. Direct measurement of intracellular pressure. The American Journal of Physiology 1991; 260: C652-C657.

17 Loewenstein WR, Kanno Y. Some electrical properties of the membrane of a cell nucleus. Nature 1962; 195: 462-464.

18 Okabe K, Inada N, Gota C et al. Intracellular temperature mapping with a fluorescent polymeric thermometer and fluorescence lifetime imaging microscopy. Nature Communications 2012; 3: 705. 
19 Liu H, Wen J, Xiao Y et al. In situ mechanical characterization of the cell nucleus by atomic force microscopy. ACS Nano 2014; 8: 3821-3828.

20 Tian B, Cohen-Karni T, Qing Q et al. Three-dimensional, flexible nanoscale fieldeffect transistors as localized bioprobes. Science 2010; 329: 830-834.

21 Sakmann B, Neher E. Patch clamp techniques for studying ionic channels in excitable membranes. Annual Review of Physiology 1984; 46: 455-472.

22 Sigworth FJ, Neher E. Single $\mathrm{Na}+$ channel currents observed in cultured rat muscle cells. Nature 1980; 287: 447-449.

23 Rohr S. Role of gap junctions in the propagation of the cardiac action potential. Cardiovascular Research 2004; 62: 309-322.

24 Winklhofer KF, Haass C. Mitochondrial dysfunction in Parkinson's disease. Biochimica et Biophysica Acta 2010; 1802: 29-44.

25 Exner N, Lutz AK, Haass C et al. Mitochondrial dysfunction in Parkinson's disease: Molecular mechanisms and pathophysiological consequences. The EMBO Journal 2012; 31: 3038-3062

$26 \mathrm{Hu}$ J, Odom TW, Lieber CM. Chemistry and physics in one dimension: Synthesis and properties of nanowires and nanotubes. Accounts of Chemical Research 1999; 32: 435-445.

27 Chen K-I, Li B-R, Chen Y-T. Silicon nanowire field-effect transistor-based biosensors for biomedical diagnosis and cellular recording investigation. Nano Today 2011; 6: 131-154.

28 Jiang Z, Qing Q, Xie $\mathrm{P}$ et al. Kinked p-n junction nanowire probes for high spatial resolution sensing and intracellular recording. Nano Letters 2012; 12 : 1711-1716.

29 Tian B, Xie P, Kempa TJ et al. Single-crystalline kinked semiconductor nanowire superstructures. Nature Nanotechnology 2009; 4: 824-829.

30 Bers DM. Cardiac excitation-contraction coupling. Nature 2002; 415: 198-205.

31 Duan X, Gao R, Xie P et al. Intracellular recordings of action potentials by an extracellular nanoscale field-effect transistor. Nature Nanotechnology 2012; 7: 174-179.

32 Fu T-M, Duan X, Jiang Z et al. Sub-10-nm intracellular bioelectronic probes from nanowire-nanotube heterostructures. Proceedings of the National Academy of Sciences of the United States of America 2014; 111: 1259-1264.

33 Robinson JT, Jorgolli M, Shalek AK et al. Vertical nanowire electrode arrays as a scalable platform for intracellular interfacing to neuronal circuits. Nature Nanotechnology 2012; 7: 180-184.

34 Singhal R, Orynbayeva Z, Kalyana Sundaram RV et al. Multifunctional carbonnanotube cellular endoscopes. Nature Nanotechnology 2011; 6: 57-64.

35 Yan R, Park J-H, Choi Y et al. Nanowire-based single-cell endoscopy. Nature Nanotechnology 2012; 7: 191-196.

36 Xie C, Lin Z, Hanson L et al. Intracellular recording of action potentials by nanopillar electroporation. Nature Nanotechnology 2012; 7: 185-190.

37 Hai A, Shappir J, Spira ME. In-cell recordings by extracellular microelectrodes. Nature Methods 2010; 7: 200-202.

38 Lin ZC, Xie C, Osakada Y et al. Iridium oxide nanotube electrodes for sensitive and prolonged intracellular measurement of action potentials. Nature Communications 2014; 5: 1-10.

39 Shalek AK, Robinson JT, Karp ES et al. Vertical silicon nanowires as a universal platform for delivering biomolecules into living cells. Proceedings of the National Academy of Sciences of the United States of America 2010; 107: 1870-1875.

40 Gao Y, Longenbach T, Vitol EA et al. One-dimensional nanoprobes for single-cell studies. Nanomedicine 2014; 9: 153-168.

41 Mahar B, Laslau C, Yip R et al. Development of carbon nanotube-based sensors -a review. IEEE Sensors Journal 2007; 7: 266-284.

42 Peng $B$, Locascio $M$, Zapol $P$ et al. Measurements of near-ultimate strength for multiwalled carbon nanotubes and irradiation-induced crosslinking improvements. Nature Nanotechnology 2008; 3: 626-631.

43 Hong S, Myung S. Nanotube electronics: A flexible approach to mobility. Nature Nanotechnology 2007; 2: 207-208.

44 Schrlau MG, Falls EM, Ziober BL et al. Carbon nanopipettes for cell probes and intracellular injection. Nanotechnology 2008; 19: 015101.

45 Schrlau MG, Dun NJ, Bau HH. Cell electrophysiology with carbon nanopipettes. ACS Nano 2009; 3: 563-568.

46 Singhal R, Bhattacharyya S, Orynbayeva Z et al. Small diameter carbon nanopipettes. Nanotechnology 2010; 21: 015304.

47 Freedman JR, Mattia D, Korneva G et al. Magnetically assembled carbon nanotube tipped pipettes. Applied Physics Letters 2007; 90: 103108.

48 Kouklin NA, Kim WE, Lazareck AD et al. Carbon nanotube probes for single-cell experimentation and assays. Applied Physics Letters 2005; 87: 173901.

49 Vakarelski IU, Brown SC, Higashitani K et al. Penetration of living cell membranes with fortified carbon nanotube tips. Langmuir: The ACS Journal of Surfaces and Colloids 2007; 23: 10893-10896.

50 Pozzan T, Rizzuto $\mathrm{R}$, Volpe $\mathrm{P}$ et al. Molecular and cellular physiology of intracellular calcium stores. Physiological Reviews 1994; 74: 595-636.

51 Yoon I, Hamaguchi K, Borzenets I V et al. Intracellular neural recording with pure carbon nanotube probes. PLoS One 2013; 8: e65715.
52 Yun Y, Dong Z, Shanov VN et al. Electrochemical impedance measurement of prostate cancer cells using carbon nanotube array electrodes in a microfluidic channel. Nanotechnology 2007; 18: 465505.

53 Li Y, Syed L, Liu J et al. Label-free electrochemical impedance detection of kinase and phosphatase activities using carbon nanofiber nanoelectrode arrays. Analytica Chimica Acta 2012; 744: 45-53.

54 McKnight TE, Melechko AV, Griffin GD et al. Intracellular integration of synthetic nanostructures with viable cells for controlled biochemical manipulation. Nanotechnology 2003; 14: 551-556.

55 Gustafsson MGL. Nonlinear structured-illumination microscopy: Wide-field fluorescence imaging with theoretically unlimited resolution. Proceedings of the National Academy of Sciences of the United States of America 2005; 102: 13081-13086.

56 Betzig E, Trautman JK. Near-field optics: Microscopy, spectroscopy, and surface modification beyond the diffraction limit. Science 1992; 257: 189-195.

57 Law M, Sirbuly DJ, Johnson JC et al. Nanoribbon waveguides for subwavelength photonics integration. Science 2004; 305: 1269-1273.

58 Sirbuly DJ, Law M, Pauzauskie $P$ et al. Optical routing and sensing with nanowire assemblies. Proceedings of the National Academy of Sciences of the United States of America 2005; 102: 7800-7805.

59 Shambat G, Kothapalli S-R, Provine J et al. Single-cell photonic nanocavity probes. Nano Letters 2013; 13: 4999-5005.

60 Beard JD, Guy RH, Gordeev SN. Mechanical tomography of human corneocytes with a nanoneedle. The Journal of Investigative Dermatology 2013; 133: 1565-1571.

61 Dai H, Hafner JH, Rinzler AG et al. Nanotubes as nanoprobes in scanning probe microscopy. Nature 1996; 384: 147-150.

62 Cheung CL, Hafner JH, Lieber CM. Carbon nanotube atomic force microscopy tips: Direct growth by chemical vapor deposition and application to highresolution imaging. Proceedings of the National Academy of Sciences of the United States of America 2000; 97: 3809-3813.

63 Yum K, Wang N, Yu M-F. Nanoneedle: A multifunctional tool for biological studies in living cells. Nanoscale 2010; 2: 363-372.

64 Obataya I, Nakamura C, Han S et al. Nanoscale operation of a living cell using an atomic force microscope with a nanoneedle. Nano Letters 2005; 5: 27-30.

65 Han SW, Nakamura C, Obataya I et al. A molecular delivery system by using AFM and nanoneedle. Biosensors \& Bioelectronics 2005; 20: 2120-2125.

66 Engstrom DS, Savu V, Zhu X et al. High throughput nanofabrication of silicon nanowire and carbon nanotube tips on AFM probes by stencil-deposited catalysts. Nano Letters 2011; 11: 1568-1574.

67 Nishijima H, Kamo S, Akita S et al. Carbon-nanotube tips for scanning probe microscopy: Preparation by a controlled process and observation of deoxyribonucleic acid. Applied Physics Letters 1999; 74: 4061.

68 Hafner JH, Cheung CL, Lieber CM. Growth of nanotubes for probe microscopy tips. Nature 1999; 398: 761-762.

69 Smoyer CJ, Jaspersen SL. Breaking down the wall: The nuclear envelope during mitosis. Current Opinion in Cell Biology 2014; 26: 1-9.

70 Wen $\mathrm{JH}$, Vincent LG, Fuhrmann A et al. Interplay of matrix stiffness and protein tethering in stem cell differentiation. Nature Materials 2014; 13: 979-987.

71 Kucsko G, Maurer PC, Yao NY et al. Nanometre-scale thermometry in a living cell. Nature 2013; 500: 54-58.

72 Burns A, Sengupta P, Zedayko T et al. Core/Shell fluorescent silica nanoparticles for chemical sensing: Towards single-particle laboratories. Small 2006; 2: 723-726.

73 Ruedas-Rama MJ, Walters JD, Orte A et al. Fluorescent nanoparticles for intracellular sensing: A review. Analytica Chimica Acta 2012; 751: 1-23.

74 Schulz A, McDonagh C. Intracellular sensing and cell diagnostics using fluorescent silica nanoparticles. Soft Matter 2012; 8: 2579.

75 Wang S, Westcott S, Chen W. Nanoparticle luminescence thermometry. The Journal of Physical Chemistry B 2002; 106: 11203-11209.

76 Maestro LM, Rodríguez EM, Rodríguez FS et al. CdSe quantum dots for twophoton fluorescence thermal imaging. Nano Letters 2010; 10: 5109-5115.

77 Yang J-M, Yang H, Lin L. Quantum dot nano thermometers reveal heterogeneous local thermogenesis in living cells. ACS Nano 2011; 5: 5067-5071.

78 De Meis L, Ketzer LA, Da Costa RM et al. Fusion of the endoplasmic reticulum and mitochondrial outer membrane in rats brown adipose tissue: activation of thermogenesis by $\mathrm{Ca}^{2+}$. PLoS One 2010; 5: e9439.

79 Lamond Al, Earnshaw WC. Structure and function in the nucleus. Science 1998; 280: $547-553$.

80 Doxsey S. Re-evaluating centrosome function. Nature Reviews Molecular Cell Biology 2001; 2: 688-698.

81 Si D, Epstein T, Lee Y-EK et al. Nanoparticle PEBBLE sensors for quantitative nanomolar imaging of intracellular free calcium ions. Analytical Chemistry 2012; 84: 978-986.

82 Seo S, Lee HY, Park M et al. Fluorescein-functionalized silica nanoparticles as a selective fluorogenic chemosensor for $\mathrm{Cu}^{2+}$ in living cells. European Journal of Inorganic Chemistry 2010; 2010: 843-847. 
83 Sarkar K, Dhara K, Nandi M et al. Selective zinc(II)- ion fluorescence sensing by a functionalized mesoporous material covalently grafted with a fluorescent chromophore and consequent biological applications. Advanced Functional Materials 2009; 19: 223-234.

84 Clark HA, Kopelman R, Tjalkens R et al. Optical nanosensors for chemical analysis inside single living cells. 2. Sensors for $\mathrm{pH}$ and calcium and the intracellular application of PEBBLE sensors. Analytical Chemistry 1999; 71: 4837-4843.

85 Peng J, He X, Wang $\mathrm{K}$ et al. Noninvasive monitoring of intracellular $\mathrm{pH}$ change induced by drug stimulation using silica nanoparticle sensors. Analytical and Bioanalytical Chemistry 2007; 388: 645-654.

86 Clark HA, Hoyer M, Philbert MA et al. Optical nanosensors for chemical analysis inside single living cells. 1. Fabrication, characterization, and methods for intracellular delivery of PEBBLE sensors. Analytical Chemistry 1999; 71: 4831-4836.

87 Norenberg MD, Rao KVR. The mitochondrial permeability transition in neurologic disease. Neurochemistry International 2007; 50: 983-997.

88 Burns A, Ow H, Wiesner U. Fluorescent core-shell silica nanoparticles: Towards 'lab on a particle' architectures for nanobiotechnology. Chemical Society Reviews 2006; 35: 1028-1042.

89 Korzeniowska B, Woolley R, DeCourcey J et al. Intracellular pH-sensing using core/shell silica nanoparticles. Journal of Biomedical Nanotechnology 2014; 10: 1336-1345.

90 Casey JR, Grinstein S, Orlowski J. Sensors and regulators of intracellular $\mathrm{pH}$. Nature Reviews Molecular Cell Biology 2010; 11: 50-61.

91 Lovrić J, Cho SJ, Winnik FM et al. Unmodified cadmium telluride quantum dots induce reactive oxygen species formation leading to multiple organelle damage and cell death. Chemistry \& Biology 2005; 12: 1227-1234.

92 Choi AO, Brown SE, Szyf M et al. Quantum dot-induced epigenetic and genotoxic changes in human breast cancer cells. Journal of Molecular Medicine 2008; 86: 291-302.

93 Dubertret B, Skourides P, Norris DJ et al. In vivo imaging of quantum dots encapsulated in phospholipid micelles. Science 2002; 298: 1759-1762.

$94 \mathrm{Liu} \mathrm{T,} \mathrm{Li} \mathrm{L,} \mathrm{Fu} \mathrm{C} \mathrm{et} \mathrm{al.} \mathrm{Pathological} \mathrm{mechanisms} \mathrm{of} \mathrm{liver} \mathrm{injury} \mathrm{caused} \mathrm{by}$ continuous intraperitoneal injection of silica nanoparticles. Biomaterials 2012; 33: 2399-2407.

95 Verma A, Stellacci F. Effect of surface properties on nanoparticle-cell interactions. Small 2010; 6: 12-21.

96 Grashoff C, Hoffman BD, Brenner MD et al. Measuring mechanical tension across vinculin reveals regulation of focal adhesion dynamics. Nature 2010; 466: 263-266.

97 Wang Y, Botvinick EL, Zhao $Y$ et al. Visualizing the mechanical activation of Src. Nature 2005; 434: 1040-1045

98 Kuimova MK, Botchway SW, Parker AW et al. Imaging intracellular viscosity of a single cell during photoinduced cell death. Nature Chemistry 2009; 1: 69-73.

99 Miesenböck G, De Angelis DA, Rothman JE. Visualizing secretion and synaptic transmission with $\mathrm{pH}$-sensitive green fluorescent proteins. Nature 1998; 394: 192-195.

100 Wang Y, Shyy JY-J, Chien S. Fluorescence proteins, live-cell imaging, and mechanobiology: Seeing is believing. Annual Review of Biomedical Engineering 2008; 10: 1-38.

101 Galbraith CG, Yamada KM, Sheetz MP. The relationship between force and focal complex development. The Journal of Cell Biology 2002; 159: 695-705.

102 Riveline D, Zamir E, Balaban NQ et al. Focal contacts as mechanosensors: Externally applied local mechanical force induces growth of focal contacts by an Mdia1-dependent and rock-independent mechanism. The Journal of Cell Biology 2001; 153: 1175-1186.

103 Conway DE, Breckenridge MT, Hinde E et al. Fluid shear stress on endothelial cells modulates mechanical tension across VE-cadherin and PECAM-1. Current Biology 2013; 23: 1024-1030.

104 Tzima E, Kiosses WB, del Pozo MA et al. Localized cdc42 activation, detected using a novel assay, mediates microtubule organizing center positioning in endothelial cells in response to fluid shear stress. The Journal of Biological Chemistry 2003; 278: 31020-31023.

105 Ganguli A, Persson L, Palmer IR et al. Distinct NF-kappaB regulation by shear stress through Ras-dependent IkappaB alpha oscillations: Real-time analysis of flow-mediated activation in live cells. Circulation Research 2005; 96: 626-634.

106 Rowat AC, Lammerding J, Ipsen JH. Mechanical properties of the cell nucleus and the effect of emerin deficiency. Biophysical Journal 2006; 91: 4649-4664.

107 Booth-Gauthier EA, Alcoser TA, Yang G et al. Force-induced changes in subnuclear movement and rheology. Biophysical Journal 2012; 103: 2423-2431.

108 Kuimova MK, Yahioglu G, Levitt JA et al. Molecular rotor measures viscosity of live cells via fluorescence lifetime imaging. Journal of the American Chemical Society 2008; 130: 6672-6673.

109 Haidekker MA, Brady TP, Lichlyter D et al. A ratiometric fluorescent viscosity sensor. Journal of the American Chemical Society 2006; 128: 398-399.
110 Guo J, Sachs F, Meng F. Fluorescence-based force/tension sensors: A novel tool to visualize mechanical forces in structural proteins in live cells. Antioxidants \& Redox Signaling 2014; 20: 986-999.

111 Kneen M, Farinas J, Li Y et al. Green fluorescent protein as a noninvasive intracellular pH indicator. Biophysical Journal 1998; 74: 1591-1599.

112 Arosio D, Ricci F, Marchetti $L$ et al. Simultaneous intracellular chloride and $\mathrm{pH}$ measurements using a GFP-based sensor. Nature Methods 2010; 7: 516-518.

113 Wong FHC, Banks DS, Abu-Arish A et al. A molecular thermometer based on fluorescent protein blinking. Journal of the American Chemical Society 2007; 129: 10302-10303.

114 Donner JS, Thompson SA, Kreuzer MP et al. Mapping intracellular temperature using green fluorescent protein. Nano Letters 2012; 12: 2107-2111.

115 Ke G, Wang C, Ge Y et al. L-DNA molecular beacon: A safe, stable, and accurate intracellular nano-thermometer for temperature sensing in living cells. Journal of the American Chemical Society 2012; 134: 18908-18911.

116 Gómez-Martínez R, Hernández-Pinto AM, Duch M et al. Silicon chips detect intracellular pressure changes in living cells. Nature Nanotechnology 2013; 8: 517-521.

117 Rajagopalan J, Saif MTA. MEMS sensors and microsystems for cell mechanobiology. Journal of Micromechanics and Microengineering 2011; 21: 54002-54012.

118 Sun Y, Nelson BJ. MEMS for cellular force measurements and molecular detection. International Journal of Information Acquisition 2004; 1: 23-32.

119 Cross SE, Jin Y-S, Rao J et al. Nanomechanical analysis of cells from cancer patients. Nature Nanotechnology 2007; 2: 780-783.

120 Novo S, Barrios L, Santaló J et al. A novel embryo identification system by direct tagging of mouse embryos using silicon-based barcodes. Human Reproduction 2011; 26: 96-105.

121 Fernandez-Rosas E, Gómez R, lbañez E et al. Intracellular polysilicon barcodes for cell tracking. Small 2009; 5: 2433-2439.

122 Orynbayeva Z, Singhal R, Vitol EA et al. Physiological validation of cell health upon probing with carbon nanotube endoscope and its benefit for single-cell interrogation. Nanomedicine 2012; 8: 590-598.

123 Han S-W, Nakamura C, Kotobuki N et al. High-efficiency DNA injection into a single human mesenchymal stem cell using a nanoneedle and atomic force microscopy. Nanomedicine: Nanotechnology, Biology, and Medicine 2008; 4: 215-225.

124 Han S, Nakamura C, Obataya I et al. Gene expression using an ultrathin needle enabling accurate displacement and low invasiveness. Biochemical and Biophysical Research Communications 2005; 332: 633-639.

125 Kihara T, Yoshida N, Mieda S et al. Nanoneedle surface modification with 2methacryloyloxyethyl phosphorylcholine polymer to reduce nonspecificprotein adsorption in a living cell. NanoBiotechnology 2008; 3: 127-134.

126 Han S-W, Nakamura C, Imai Y et al. Monitoring of hormonal drug effect in a single breast cancer cell using an estrogen responsive GFP reporter vector delivered by a nanoneedle. Biosensors \& Bioelectronics 2009; 24: 1219-1222.

127 Chen X, Kis A, Zettl A et al. A cell nanoinjector based on carbon nanotubes. Proceedings of the National Academy of Sciences of the United States of America 2007; 104: 8218-8222.

128 Yum K, Na S, Xiang Y et al. Mechanochemical delivery and dynamic tracking of fluorescent quantum dots in the cytoplasm and nucleus of living cells. Nano Letters 2009; 9: 2193-2198.

129 Kim W, Ng JK, Kunitake ME et al. Interfacing silicon nanowires with mammalian cells. Journal of the American Chemical Society 2007; 129: 7228-7229.

130 Hällström W, Mårtensson T, Prinz C et al. Gallium phosphide nanowires as a substrate for cultured neurons. Nano Letters 2007; 7: 2960-2965.

131 Jiang K, Fan D, Belabassi $Y$ et al. Medicinal surface modification of silicon nanowires: Impact on calcification and stromal cell proliferation. ACS Applied Materials \& Interfaces 2009; 1: 266-269.

132 Qi S, Yi C, Ji S et al. Cell adhesion and spreading behavior on vertically aligned silicon nanowire arrays. ACS Applied Materials \& Interfaces 2009; 1: 30-34.

133 Guignet EG, Meyer T. Suspended-drop electroporation for high-throughput delivery of biomolecules into cells. Nature Methods 2008; 5: 393-395.

134 Boukany PE, Morss A, Liao W et al. Nanochannel electroporation delivers precise amounts of biomolecules into living cells. Nature Nanotechnology 2011; 6: 747-754.

$135 \mathrm{Kim} \mathrm{HJ,} \mathrm{Greenleaf} \mathrm{JF,} \mathrm{Kinnick} \mathrm{RR} \mathrm{et} \mathrm{al.} \mathrm{Ultrasound-mediated} \mathrm{transfection} \mathrm{of}$ mammalian cells. Human Gene Therapy 1996; 7: 1339-1346.

136 Mitragotri S. Healing sound: the use of ultrasound in drug delivery and other therapeutic applications. Nature Reviews Drug Discovery 2005; 4: 255-260.

137 Tirlapur UK, König K. Targeted transfection by femtosecond laser. Nature 2002; 418: $290-291$.

138 Chakravarty P, Qian W, El-Sayed MA et al. Delivery of molecules into cells using carbon nanoparticles activated by femtosecond laser pulses. Nature Nanotechnology 2010; 5: 607-611.

139 Neumann E, Schaefer-Ridder M, Wang Y et al. Gene transfer into mouse lyoma cells by electroporation in high electric fields. The EMBO Journal 1982; 1: 841-845. 
140 Fox MB, Esveld DC, Valero A et al. Electroporation of cells in microfluidic devices: A review. Analytical and Bioanalytical Chemistry 2006; 385: 474-485.

141 Ho SY, Mittal GS. Electroporation of cell membranes: A review. Critical Reviews in Biotechnology 1996; 16: 349-362.

142 Kotnik T, Frey W, Sack M et al. Electroporation-based applications in biotechnology. Trends in Biotechnology 2015; 33: 480-488.

143 Wu Y-C, Wu T-H, Clemens DL et al. Massively parallel delivery of large cargo into mammalian cells with light pulses. Nature Methods 2015; 12: 439-444.

144 Tay AK, Dhar M, Pushkarsky I et al. Research highlights: Manipulating cells inside and out. Lab on a Chip 2015; 15: 2533-2537.

145 Doherty GJ, McMahon HT. Mechanisms of endocytosis. Annual Review of Biochemistry 2009; 78: 857-902.

146 Benmerah A, Lamaze C. Clathrin-coated pits: Vive la différence? Traffic 2007; 8: 970-982.

147 Zhang S, Li J, Lykotrafitis G et al. Size-dependent endocytosis of nanoparticles. Advanced Materials 2009; 21: 419-424.

148 Vácha R, Martinez-Veracoechea FJ, Frenkel D. Receptor-mediated endocytosis of nanoparticles of various shapes. Nano Letters 2011; 11: 5391-5395.

149 Iversen T-G, Skotland T, Sandvig K. Endocytosis and intracellular transport of nanoparticles: Present knowledge and need for future studies. Nano Today 2011; 6: 176-185.

150 Jiang W, Kim BYS, Rutka JT et al. Nanoparticle-mediated cellular response is size-dependent. Nature Nanotechnology 2008; 3: 145-150.

151 Jin H, Heller DA, Sharma R et al. Size-dependent cellular uptake and expulsion of single-walled carbon nanotubes: Single particle tracking and a generic uptake model for nanoparticles. ACS Nano 2009; 3: 149-158.

152 Chithrani BD, Chan WCW. Elucidating the mechanism of cellular uptake and removal of protein-coated gold nanoparticles of different sizes and shapes. Nano Letters 2007; 7: 1542-1550.

153 Qiu Y, Liu Y, Wang L et al. Surface chemistry and aspect ratio mediated cellular uptake of Au nanorods. Biomaterials 2010; 31: 7606-7619.

154 Oh N, Park J-H. Endocytosis and exocytosis of nanoparticles in mammalian cells. International Journal of Nanomedicine 2014; 9: 51-63.

155 Chithrani BD, Ghazani AA, Chan WCW. Determining the size and shape dependence of gold nanoparticle uptake into mammalian cells. Nano Letters 2006; 6: 662-668.

156 Lee J, Kim J, Park E et al. PEG-ylated cationic CdSe/ZnS QDs as an efficient intracellular labeling agent. Physical Chemistry Chemical Physics 2008; 10: 1739-1742.

157 Chung T-H, Wu S-H, Yao M et al. The effect of surface charge on the uptake and biological function of mesoporous silica nanoparticles in 3T3-L1 cells and human mesenchymal stem cells. Biomaterials 2007; 28: 2959-2966.

158 Choi CHJ, Hao L, Narayan SP et al. Mechanism for the endocytosis of spherical nucleic acid nanoparticle conjugates. Proceedings of the National Academy of Sciences of the United States of America 2013; 110: 7625-7630.

159 Gao H, Yang Z, Zhang S et al. Ligand modified nanoparticles increases cell uptake, alters endocytosis and elevates glioma distribution and internalization. Scientific Reports 2013; 3: 2534.

160 Nativo P, Prior IA, Brust M. Uptake and intracellular fate of surface-modified gold nanoparticles. ACS Nano 2008; 2: 1639-1644.

161 Delehanty JB, Bradburne $\mathrm{CE}$, Boeneman $\mathrm{K}$ et al. Delivering quantum dotpeptide bioconjugates to the cellular cytosol: Escaping from the endolysosomal system. Integrative Biology 2010; 2: 265-277.

162 Chu Z, Sun Y, Kuan CY et al. Saposin C: Neuronal effect and CNS delivery by liposomes. Annals of the New York Academy of Sciences 2005; 1053: 237-246.

163 Sneh-Edri H, Likhtenshtein D, Stepensky D. Intracellular targeting of PLGA nanoparticles encapsulating antigenic peptide to the endoplasmic reticulum of dendritic cells and its effect on antigen cross-presentation in vitro. Molecular Pharmaceutics 2011; 8: 1266-1275.

164 De la Fuente JM, Berry CC. Tat peptide as an efficient molecule to translocate gold nanoparticles into the cell nucleus. Bioconjugate Chemistry 2005; 16: 1176-1180.

165 Savic R, Luo L, Eisenberg A et al. Micellar nanocontainers distribute to defined cytoplasmic organelles. Science 2003; 300: 615-618.

166 Ruan G, Agrawal A, Marcus Al et al. Imaging and tracking of tat peptideconjugated quantum dots in living cells: New insights into nanoparticle uptake, intracellular transport, and vesicle shedding. Journal of the American Chemical Society 2007; 129: 14759-14766.

167 Lewinski N, Colvin V, Drezek R. Cytotoxicity of nanoparticles. Small 2008; 4: 26-49.

168 Xia T, Li N, Nel AE. Potential health impact of nanoparticles. Annual Review of Public Health 2009; 30: 137-150.

169 Nel A, Xia T, Mädler L et al. Toxic potential of materials at the nanolevel. Science 2006; 311: 622-627.

170 Actis $\mathrm{P}$, Maalouf MM, Kim HJ et al. Compartmental genomics in living cells revealed by single-cell nanobiopsy. ACS Nano 2014; 8: 546-553.

171 Chen BK, Anchel D, Gong Z et al. Nano-dissection and sequencing of DNA at single sub-nuclear structures. Small 2014; 10: 3267-3274.
172 Li G-P, White KL, Bunch TD. Review of enucleation methods and procedures used in animal cloning: state of the art. Cloning and Stem Cells 2004; 6: 5-13.

173 Campbell KH, McWhir J, Ritchie WA et al. Sheep cloned by nuclear transfer from a cultured cell line. Nature 1996; 380: 64-66.

174 Shelby JP, Edgar JS, Chiu DT. Monitoring cell survival after extraction of a single subcellular organelle using optical trapping and pulsed-nitrogen laser ablation. Photochemistry and Photobiology 2005; 81: 994-1001.

175 Ashkin A, Dziedzic JM. Internal cell manipulation using infrared laser traps. Proceedings of the National Academy of Sciences of the United States of America 1989; 86: 7914-7918.

176 Caspi A, Granek R, Elbaum M. Diffusion and directed motion in cellular transport. Physical Review E 2002; 66: 011916.

177 Jeffries GDM, Edgar JS, Zhao Y et al. Using polarization-shaped optical vortex traps for single-cell nanosurgery. Nano Letters 2007; 7: 415-420.

178 Crick FHC, Hughes AFW. The physical properties of cytoplasm. Experimental Cell Research 1950; 1: 37-80.

179 Bausch AR, Möller W, Sackmann E. Measurement of local viscoelasticity and forces in living cells by magnetic tweezers. Biophysical Journal 1999; 76: 573-579.

180 Kanger JS, Subramaniam V, van Driel R. Intracellular manipulation of chromatin using magnetic nanoparticles. Chromosome Research 2008; 16: 511-522.

181 Feneberg W, Westphal M, Sackmann E. Dictyostelium cells' cytoplasm as an active viscoplastic body. European Biophysics Journal 2001; 30: 284-294.

182 Strick TR, Allemand JF, Bensimon D et al. The elasticity of a single supercoiled DNA molecule. Science 1996; 271: 1835-1837.

183 Bausch AR, Ziemann F, Boulbitch AA et al. Local measurements of viscoelastic parameters of adherent cell surfaces by magnetic bead microrheometry. Biophysical Journal 1998; 75: 2038-2049.

184 De Vries AHB, Krenn BE, van Driel R et al. Direct observation of nanomechanical properties of chromatin in living cells. Nano Letters 2007; 7: 1424-1427.

185 Fisher JK, Cummings JR, Desai KV. et al. Three-dimensional force microscope: A nanometric optical tracking and magnetic manipulation system for the biomedical sciences. Review of Scientific Instruments 2005; 76: 053711.

186 Kang S-T, Yeh C-K. Intracellular acoustic droplet vaporization in a single peritoneal macrophage for drug delivery applications. Langmuir: The ACS Journal of Surfaces and Colloids 2011; 27: 13183-13188.

187 Fan Z, Sun Y, Di Chen et al. Acoustic tweezing cytometry for live-cell subcellular modulation of intracellular cytoskeleton contractility. Scientific Reports 2013; 3: 2176.

188 Vetrone F, Naccache R, Zamarrón A et al. Temperature sensing using fluorescent nanothermometers. ACS Nano 2010; 4: 3254-3258.

189 Rossi AE, Dirksen RT. Sarcoplasmic reticulum: the dynamic calcium governor of muscle. Muscle \& Nerve 2006; 33: 715-731.

190 Micaroni M. Calcium around the Golgi apparatus: implications for intracellular membrane trafficking. Advances in Experimental Medicine and Biology 2012; 740: 439-460.

191 Geim AK, Novoselov KS. The rise of graphene. Nature Materials 2007; 6: 183-191.

192 Hess LH, Jansen M, Maybeck V et al. Graphene transistor arrays for recording action potentials from electrogenic cells. Advanced Materials 2011; 23: 5045-5049, 4968.

193 Cohen-Karni T, Qing Q, Li Q et al. Graphene and nanowire transistors for cellular interfaces and electrical recording. Nano Letters 2010; 10: 1098-1102.

194 Liu J, Gong Z, Tang K et al. Locating end-effector tips in robotic micromanipulation. IEEE Transactions on Robotics 2014; 30: 125-130.

195 Liu J, Siragam V, Chen J et al. High-throughput measurement of gap junctional intercellular communication. American Journal of Physiology Heart and Circulat ory Physiology 2014; 306: $\mathrm{H} 1708-\mathrm{H} 1713$.

196 Liu J, Siragam V, Gong Z et al. Robotic adherent cell injection for characterizing cell-cell communication. IEEE Transactions on Bio-Medical Engineering 2015; 62 119-125.

197 Hagiwara M, Kawahara T, Yamanishi $Y$ et al. On-chip magnetically actuated robot with ultrasonic vibration for single cell manipulations. Lab on a Chip 2011 11: 2049-2054.

198 Tan Y, Sun D, Wang J et al. Mechanical characterization of human red blood cells under different osmotic conditions by robotic manipulation with optical tweezers. IEEE Transactions on Biomedical Engineering 2010; 57: 1816-1825.

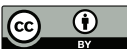

This work is licensed under a Creative Commons Attribution 4.0 Unported License. The images or other third party material in this article are included in the article's Creative Commons license, unless indicated otherwise in the credit line; if the material is not included under the Creative Commons license, users will need to obtain permission from the license holder to reproduce the material. To view a copy of this license, visit http://creativecommons. org/licenses/by/4.0 